\title{
Contaminant and Environmental Influences on Thyroid Hormone Action in Amphibian Metamorphosis
}

\author{
Anita A. Thambirajah ${ }^{\dagger}$, Emily M. Koide ${ }^{\dagger}$, Jacob J. Imbery and Caren C. Helbing * \\ Department of Biochemistry and Microbiology, University of Victoria, Victoria, BC, Canada
}

Aquatic and terrestrial environments are increasingly contaminated by anthropogenic sources that include pharmaceuticals, personal care products, and industrial and agricultural chemicals (i. e., pesticides). Many of these substances have the potential to disrupt endocrine function, yet their effect on thyroid hormone (TH) action has garnered relatively little attention. Anuran postembryonic metamorphosis is strictly dependent on $\mathrm{TH}$ and perturbation of this process can serve as a sensitive barometer for the detection and mechanistic elucidation of $\mathrm{TH}$ disrupting activities of chemical

OPEN ACCESS

Edited by:

Laurent M. Sachs,

Muséum National d'Histoire Naturelle,

France

Reviewed by:

Daniel Buchholz,

University of Cincinnati, United States

Paul Webb,

California Institute for Regenerative

Medicine, United States

${ }^{*}$ Correspondence: Caren C. Helbing chelbing@uvic.ca

tThese authors have contributed equally to this work

Specialty section: This article was submitted to

Thyroid Endocrinology,

a section of the journal Frontiers in Endocrinology

Received: 31 January 2019 Accepted: 16 April 2019

Published: 14 May 2019

Citation:

Thambirajah AA, Koide EM, Imbery JJ and Helbing CC (2019) Contaminant and Environmental Influences on Thyroid Hormone Action in Amphibian Metamorphosis.

Front. Endocrinol. 10:276 doi: 10.3389/fendo.2019.00276 contaminants and their complex mixtures. The ecological threats posed by these contaminants are further exacerbated by changing environmental conditions such as temperature, photoperiod, pond drying, food restriction, and ultraviolet radiation. We review the current knowledge of several chemical and environmental factors that disrupt TH-dependent metamorphosis in amphibian tadpoles as assessed by morphological, thyroid histology, behavioral, and molecular endpoints. Although the molecular mechanisms for TH disruption have yet to be determined for many chemical and environmental factors, several affect $\mathrm{TH}$ synthesis, transport or metabolism with subsequent downstream effects. As molecular dysfunction typically precedes phenotypic or histological pathologies, sensitive assays that detect changes in transcript, protein, or metabolite abundance are indispensable for the timely detection of $\mathrm{TH}$ disruption. The emergence and application of 'omics techniques-genomics, transcriptomics, proteomics, metabolomics, and epigenomics-on metamorphosing tadpoles are powerful emerging assets for the rapid, proxy assessment of toxicant or environmental damage for all vertebrates including humans. Moreover, these highly informative 'omics techniques will complement morphological, behavioral, and histological assessments, thereby providing a comprehensive understanding of how $\mathrm{TH}$-dependent signal disruption is propagated by environmental contaminants and factors.

Keywords: thyroid hormone, environmental contaminant, endocrine disruptor, frog tadpole, metamorphosis, environmental factors, transcriptomics, genomics

\section{INTRODUCTION}

Thyroid hormone (TH) signaling is a cornerstone of molecular events that mediate the profound morphological changes characteristic of early vertebrate development (1). The obligate requirement for $\mathrm{TH}$ is perhaps best exemplified by metamorphosing anuran amphibians for which the essential stimulation by $\mathrm{TH}$ initiates transitions from larval to juvenile stages under conducive 
environmental conditions (2). Amphibians undergo complex and comprehensive morphological changes as functionally athyroid premetamorphic tadpoles progress through prometamorphosis (with concurrent, increasing endogenous $\mathrm{TH}$ levels) and into juvenile frogs after metamorphic climax (Figure 1) (4). These changes encompass the coordinated maturation and remodeling of organs, de novo generation of limbs, regression of the tail, and the consequent alteration in behavior, diet, and niche as most aquatic tadpoles develop into more terrestrial-dwelling frogs (Figure 1) (5).

$\mathrm{TH}$ production is controlled by the hypothalamic-pituitarythyroid (HPT) axis (Figure 2). The hypothalamus stimulates the pituitary with corticotropin releasing factor (CRF) to release thyroid stimulating hormone (TSH). TSH promotes the synthesis of $\mathrm{TH}$ in the follicular cells of the thyroid gland (2). The central dogma of $\mathrm{TH}$ signaling is that the newly synthesized prohormone thyroxine $\left(\mathrm{T}_{4}\right)$ is transported from the thyroid gland by transporter proteins (e.g., transthyretin). Once at the destination peripheral tissue, $\mathrm{T}_{4}$ is converted into its more active form, 3,3',5-triodothyronine $\left(\mathrm{T}_{3}\right)$, by the enzymatic activity of deiodinases (Figure 2). Additionally, the bioactivity of $\mathrm{T}_{4}$, without conversion, has recently been demonstrated (69). $\mathrm{TH}$ binds its $\mathrm{TH}$ receptors (TRs), $\mathrm{TR} \alpha$, and $\mathrm{TR} \beta$, which are constitutively bound to cognate receptor elements that regulate genes sensitive to $\mathrm{TH}$. Metamorphosis is initiated in anurans upon $\mathrm{TH}$ production, which stimulates gene expression cascades and subsequent proteomic and metabolomic alterations (Figure 2) (10, 11). TH metabolism is regulated through various enzymatic activities (glucuronidation, sulfation, and deiodination), which can target the hormone for degradation and thereby modulate TH activation of gene expression (Figure 2). For more detailed descriptions of thyroid hormone production, activity, and metabolism, the reader is encouraged to consult the following publications and the references therein $(2,12-15)$.

The spatiotemporal control of TH-dependent molecular and physiological activities during metamorphosis is particularly sensitive to abiotic and xenobiotic perturbations. Although the mechanism of molecular interference is not known for most adverse exposures, disruption can potentially target any aspect of TH synthesis, activity, and metabolism (Figure 2). Such disruptions include the exposure of premetamorphic tadpoles to exogenous $\mathrm{TH}$, which results in a precocious induction of metamorphosis that can be exploited to experimentally assess toxicant perturbations during this developmental period (2).

In the present review, we discuss the effects of chemical and environmental disruptors of metamorphic $\mathrm{TH}$ signaling on anuran amphibians. Anurans are particularly tractable for the study of TH disruption due to the absolute necessity for $\mathrm{TH}$ to initiate metamorphosis, and consequently, the well-demarcated developmental transitions in amphibians (11). Chemical disruption of anuran metamorphosis almost exclusively originates from anthropogenic sources: industry, agriculture,

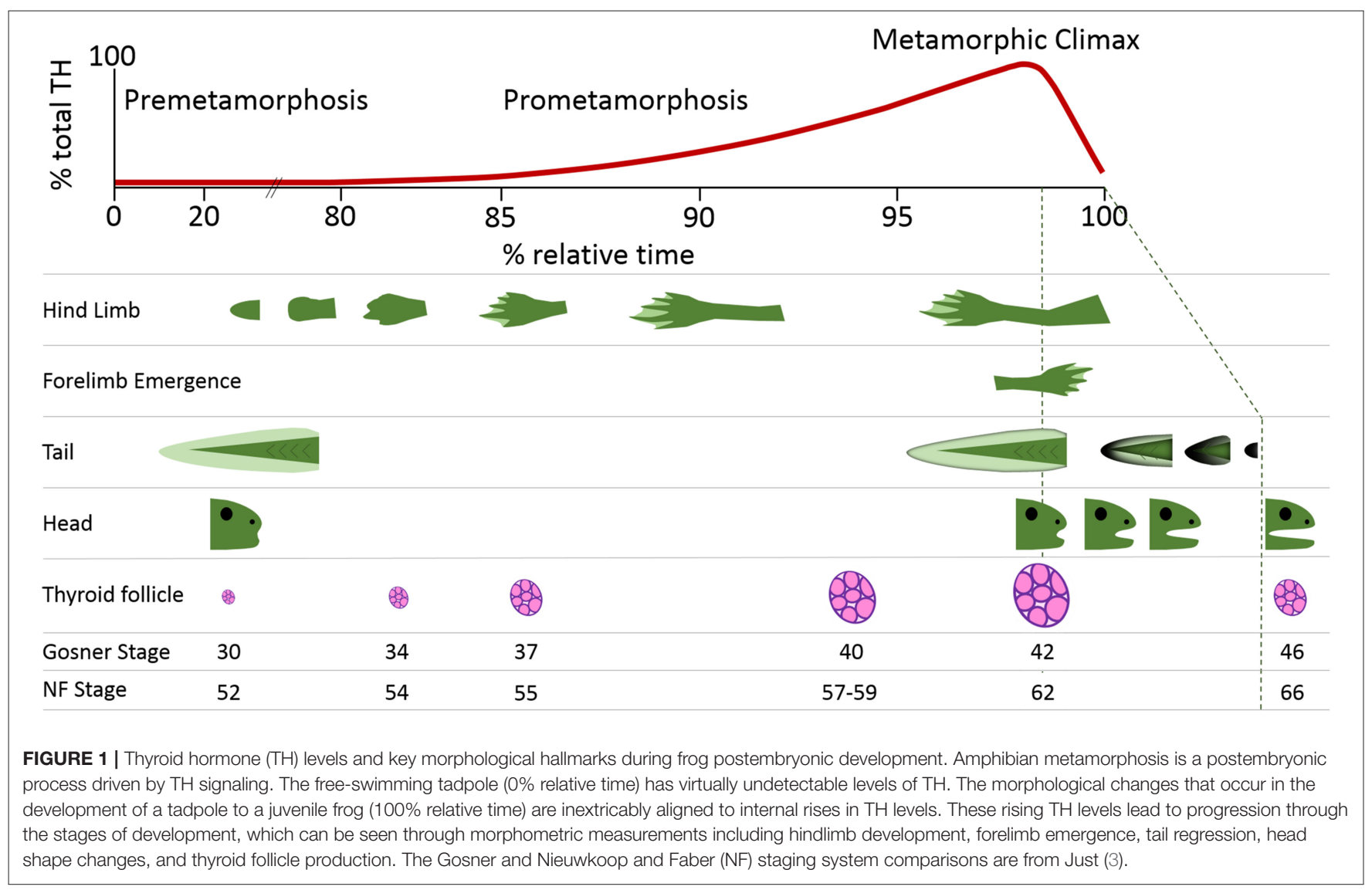




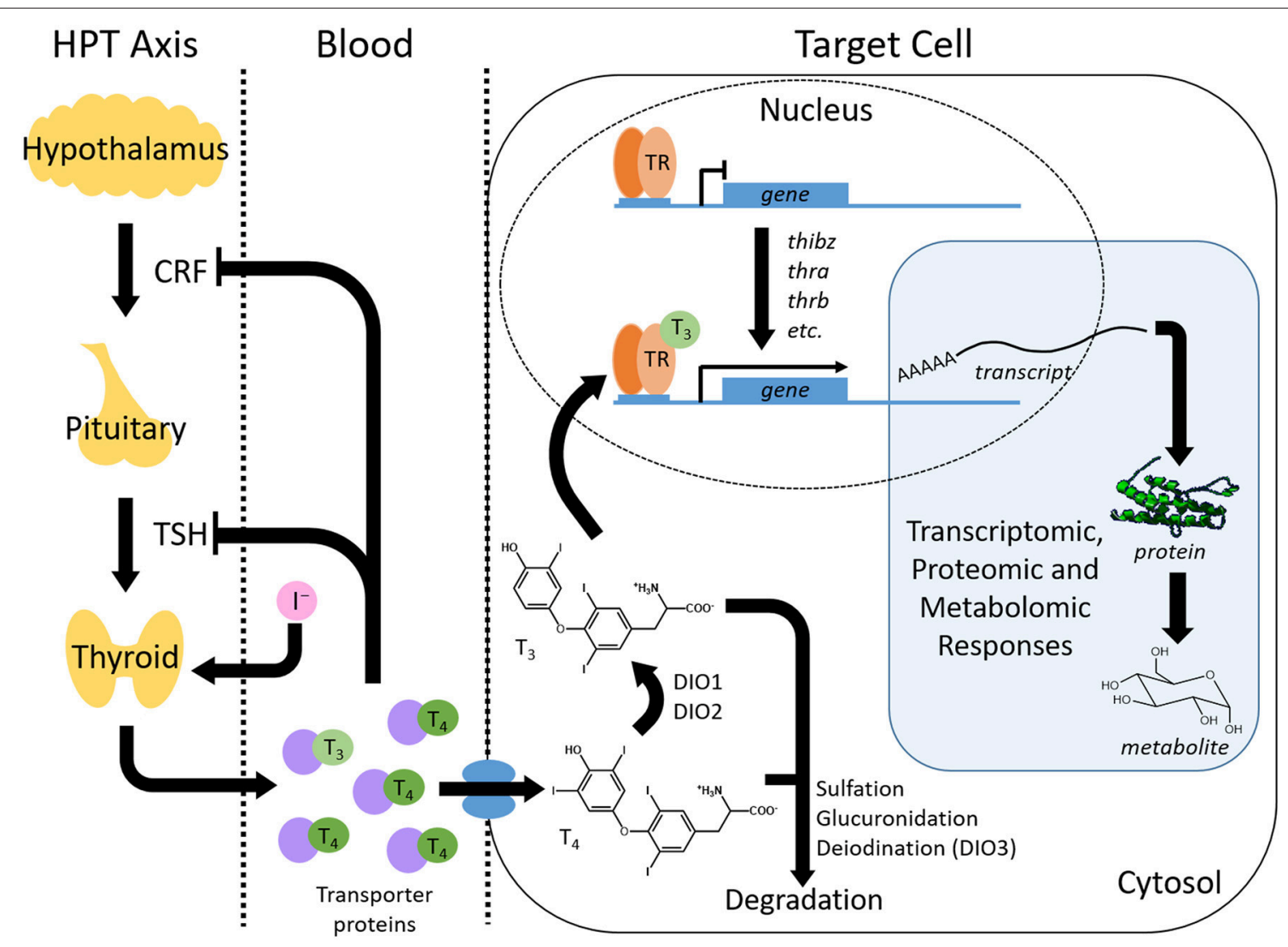

FIGURE 2 | Overview of thyroid hormone (TH) production, transport, activity and regulation. The thyroid hormone signaling pathway involves a complex interplay between TH synthesis, transport, signal transduction, and catabolism. TH is synthesized within the hypothalamus-pituitary-thyroid (HPT) axis where the pituitary is stimulated to release thyroid stimulating hormone $(\mathrm{TSH})$ by corticotropin releasing factor ( $\mathrm{CRF}$ ) from the hypothalamus. TSH induces the production of thyroxine $\left(\mathrm{T}_{4}\right)$ and, in lesser amounts, triiodothyronine $\left(\mathrm{T}_{3}\right)$ from the thyroid gland. The production of TH self-regulates through a negative feedback loop that inhibits further CRF and TSH production. TH travels through the blood via transporter proteins to peripheral tissues where it is imported into target cells. Here, $\mathrm{T}_{4}$ is converted to $\mathrm{T}_{3}$ through deiodinases (DIO), although $\mathrm{T}_{4}$ can bind to receptors as well. Binding of THs to TH nuclear receptors (TR) leads to the activation of TH response genes. This change in transcript abundance results in downstream proteomic and metabolomic responses that produce the phenotypic changes resulting from the $\mathrm{TH}$ signal. The TH signal is also regulated within the cell by catabolism that includes processes such as sulfation, glucuronidation and deiodination.

pharmaceuticals, and personal care products (PPCPs; Figure 3). Additionally, environmental factors, including temperature variations and ultraviolet radiation, have demonstrated effects on metamorphosis (Figure 3). Numerous studies have examined the effects of single chemical, complex chemical mixtures, or environmental exposures on amphibian morphology during metamorphosis and we focus our discussion on those that have additionally demonstrated a $\mathrm{TH}$-dependence of these effects. Adverse toxicant and environmental exposures can compromise other endocrine and molecular signaling pathways beyond $\mathrm{TH}$, with sub-lethal physiological consequences for reproductive success, behavior, and broader dysfunction (16-19). We have restricted our discussion to select representatives from each of the major classes listed above and regret being unable to undertake an exhaustive review of all the excellent work done on TH disruptors.

The adoption of molecular biology techniques to assess the perturbation of TH-dependent metamorphosis has complemented conventional morphological characterizations and provided further insight into the sensitive responses of $\mathrm{TH}$-induced gene expression (Figure 1) (20, 21). We discuss how the application of quantitative polymerase chain reaction (qPCR), DNA microarrays, next generation sequencing and other 'omics techniques can ascertain $\mathrm{TH}$ disruption through the timely detection of biomarkers prior to the manifestation of morphological phenotypes $(11,22,23)$. A list of TH-responsive gene transcripts mentioned in the current review is presented in Table 1.

\section{PHARMACEUTICALS AND PERSONAL CARE PRODUCTS}

Pharmaceutical and personal care products (PPCPs) are an abundant source of diverse anthropogenic contaminants in global aquatic and terrestrial environments $(24,25)$. Increasing evidence links TH disruption in frogs with a variety of PPCPs, some of which are highlighted below and summarized in Table 2. 


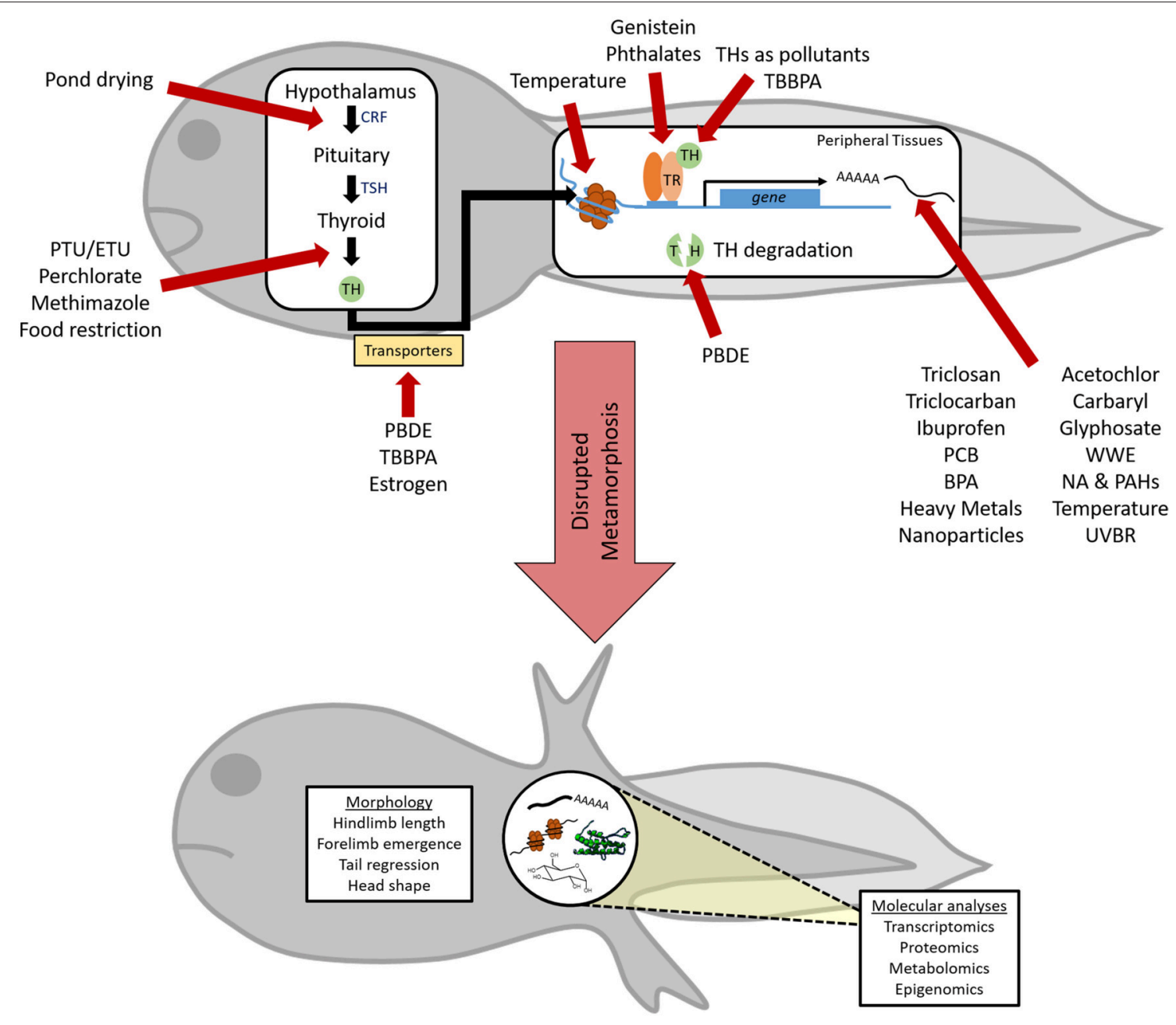

FIGURE 3 | Perturbation of thyroid hormone (TH)-dependent amphibian metamorphosis by xenobiotic and abiotic exposures. Chemical and/or environmental factors can disrupt TH action at multiple points along this pathway (red arrows), although little is known about the specific mechanism of action for many factors. Due to its absolute reliance on proper TH signaling, metamorphic endpoints can be used to reveal the TH-disrupting capabilities of these factors. However, a more complete understanding of endocrine disruption and insight into modes of action can be achieved through the use of advanced techniques to assess alterations in the transcriptome, proteome, metabolome, and epigenome within metamorphosing tadpoles. CRF, corticotropin releasing factor; TSH, thyroid stimulating hormone; TR, TH receptor; PTU, propylthiouracil; ETU, Ethylenethiourea; TBBPA, Tetrabromobisphenol A; PBDE, polybrominated diphenyl ethers; PCB, polychlorinated bisphenols; BPA, bisphenol A; NA \& PAHs, napthenic acid and polycyclic aromatic hydrocarbons; WWE, wastewater effluent; UVBR, ultraviolet B radiation.

\section{THs as Pollutants $\left(T_{3} / T_{4}\right)$}

THs can be found as pollutants in environmental water systems. As thyroid medication is the third-most prescribed drug in Canada for women aged 25-66, TH can be found in municipal wastewater (37). Brown and Wong measured the concentrations of $\mathrm{T}_{4}$ at a wastewater treatment plant in Winnipeg, Canada and found a range from 60 to $79 \mathrm{ng} / \mathrm{L}(\sim 0.1 \mathrm{nM})$ with $\mathrm{T}_{4}$ persisting through the treatment phases (38). The majority of recent studies examining precocious metamorphosis induced by THs have used physiological levels (e.g., 10-50 nM). More recently, however, studies have shown that premetamorphic tadpoles are competent to respond to lower, more environmentallyrelevant levels of $\mathrm{T}_{3}$ and $\mathrm{T}_{4}$ found in wastewater $(6,7)$. Maher et al. found that in Rana [Lithobates] (R.) catesbeiana dio2 and cebp1 are responsive to as little as $0.05 \mathrm{nM} \mathrm{T}_{4}$ in the brain and back skin, respectively (7). Slightly higher concentrations of $0.1 \mathrm{nM} \mathrm{T} \mathrm{T}_{3}$ and $0.5 \mathrm{nM} \mathrm{T} \mathrm{T}_{4}$ led to an increased number of TH-responsive transcripts such as thrb, thibz, klf9, and rlk1 in the back skin, brain, intestine, liver, and tail fin (Table 2). In the same species, Jackman et al. found that olfactory epithelium exposed to $0.5 \mathrm{nM} \mathrm{T} \mathrm{T}_{4}$ also exhibited a significant increase in thrb, thra, and thibz (7). The responsiveness of $\mathrm{TH}$-linked transcripts to environmentally-relevant levels of THs indicates that these low concentrations may be enough to affect metamorphosis. An early study demonstrating TH-induced metamorphosis found that premature induction resulted in mortality when $\mathrm{TH}$ amounts were greater than environmental levels (7). 
TABLE 1 | List of gene names utilized and their abbreviations.

\begin{tabular}{|c|c|}
\hline Abbreviation & Gene name \\
\hline ahrl & Aryl hydrocarbon receptor-like \\
\hline app & Amyloid $\beta$ precursor protein \\
\hline asl & Argininosuccinate lyase \\
\hline cebp1 & CCAAT enhancer binding protein 1 \\
\hline cebp2 & CCAAT enhancer binding protein 2 \\
\hline cebpd & CCAAT enhancer binding protein $\Delta$ \\
\hline cps 1 & Carbamoyl phosphate synthetase 1 \\
\hline crhbp & Corticotropin-releasing factor-binding protein \\
\hline dio1 & Deiodinase 1 \\
\hline dio2 & Deiodinase 2 \\
\hline dio3 & Deiodinase 3 \\
\hline fap & Fibroblast activation protein $\alpha$ \\
\hline heket & Heket \\
\hline hsp30 & Heat shock protein 30 \\
\hline ipo & Importin \\
\hline klf9 & Krüppel-like factor 9 formerly referred to as bteb \\
\hline krt1 & Cytokeratin type 1 \\
\hline$m b p$ & Myelin basic protien \\
\hline mct8 & Monocarboxylate transporter \\
\hline mmp2 & Matrix metalloproteinase 9 , formerly known as gelatinase $A$ \\
\hline mmp9 & Matrix metalloproteinase 9 , formerly known as gelatinase $B$ \\
\hline nfic & Nuclear factor I/C \\
\hline oatp1c1 & Solute carrier organic anion transporter family member 1c1 \\
\hline otc & Ornithine transcarbamylase \\
\hline pcna & Proliferating cell nuclear antigen \\
\hline pparg & Peroxisome proliferator activated receptor $\gamma$ \\
\hline prlr & Prolactin receptor \\
\hline$r \mid k 1$ & Rana larval keratin I \\
\hline$r \times r g$ & Retinoid X receptor $\gamma$ \\
\hline ssh & Sonic hedgehog \\
\hline st3 & Stromelysin 3 also known as matrix metalloprotein 11 ( $\mathrm{mmp} 11)$ \\
\hline thibz & $\begin{array}{l}\text { TH induced bZip protein formerly referred to as TH/bZip, b/Zip, } \\
\text { gene } 8 \text {, or gene } 9\end{array}$ \\
\hline thra & $\mathrm{TR} \alpha$ \\
\hline thrb & $\operatorname{TR} \beta$ \\
\hline timp2 & Tissue inhibitor of metalloproteinases 2 \\
\hline trip4 & TR interactor 4 \\
\hline tsha & Thyroid stimulating hormone $\alpha$ \\
\hline tshb & Thyroid stimulating hormone $\beta$ \\
\hline $\operatorname{ttr}$ & Transthyretin \\
\hline
\end{tabular}

Exposure to $\mathrm{T}_{3}$ is also associated with behavioral changes in which tadpoles lose the ability to detect a predator cue (36). Surprisingly, comparable $\mathrm{T}_{4}$ exposures had no effect on this behavioral endpoint (36). Molecular analyses of the olfactory epithelium using qPCR and RNA-seq methods revealed that this tissue was extraordinarily sensitive to both hormones and, while many gene responses were shared between the two hormones, a substantial number were unique to each hormone with $\mathrm{T}_{3}$ significantly affecting a $1 / 4$ more contigs than $\mathrm{T}_{4}(6,7)$. Notable differences in sensory perception, potassium ion transport, DNA repair, mitochondrial energetics and transcription/RNA processing gene ontologies provide some insight into the different effects of these hormones (36). These studies accentuate that the two TH contaminants should be treated separately when looking at responses to environmentally-relevant levels of THs.

\section{Propylthiouracil and Ethylenethiourea}

6-Propylthiouracil (PTU) is a TH synthesis antagonist that is clinically used to treat hyperthyroidism. Ethylenethiourea (ETU) is also an anti-thyroidal compound that, similar to PTU, inhibits thyroid peroxidase, the enzyme that synthesizes TH (39). Xenopus (X.) laevis tadpoles independently exposed to PTU and ETU had inhibited metamorphic progression $(30,40)$. X. laevis tadpoles exposed to ETU at stage 51 exhibited delays and arrest of natural metamorphosis, as measured by forelimb emergence (21). Histological aberrations in thyroid gland formation were evident with increased glandular size and follicle size and partial colloid depletion following exposures to ETU and PTU $(21,30)$. Elevated abundance of tsha and tsh $b$ transcripts were measured by qPCR in the pituitary tissue of tadpoles exposed to ETU (21). Similar metamorphic delays and aberrant thyroid gland histology were also observed in X. (Silurana) tropicalis and $R$. rugosa tadpoles following PTU exposures $(41,42)$.

Early prometamorphic $X$. laevis tadpoles (Niewkoop and Faber [NF] stage 54) exposed to $20 \mathrm{mg} / \mathrm{L}$ PTU did not have significantly altered thra, thrb, or klf9 transcript abundance in the brain, hindlimb or tail $(31,43)$. MAGEX cDNA array analysis of naturally metamorphosing $X$. laevis tadpoles at NF stage 54 exposed to PTU recorded a greater number of transcripts with decreased abundance than increased abundance in the brain at 24, 48, and $96 \mathrm{~h}$ post-treatment (Table 2) (32). Differential transcription was ontologically associated with transcriptional regulation at $24 \mathrm{~h}$ and at $96 \mathrm{~h}$, transcription, hormonal regulation and structural proteins (32). Correspondence analysis was used to identify possible metamorphic biomarker candidates and qPCR analyses confirmed the increased expression of myelin basic protein $(m b p)$ and myelin proteolipid protein $(p l p)$ in the brain upon PTU exposure (Table 2) (32). Using similar experimental conditions, the PTU-dependent effects were further examined in the $X$. laevis hindlimb and tail (34). Seven transcripts were identified by cDNA arrays to have differential abundance in the hindlimb at 24 and $96 \mathrm{~h}$ post-exposure and were associated with hormonal regulation and structural proteins at $24 \mathrm{~h}$ and protein processing, transcription, and transport and binding at $96 \mathrm{~h}$ (Table 2) (34). Using cDNA arrays, 4 transcripts were detected to have differential levels in the tail at $48 \mathrm{~h}$ and were linked to transcription, cell growth control, and transport and binding ontologies (Table 2) (34). Potential biomarkers were screened using qPCR and cytokeratin type I (krtl) transcripts were elevated significantly in both the hindlimb and tail (Table 2) (34).

Naturally metamorphosing $X$. laevis tadpoles exposed to ETU exhibited developmental arrest and aberrant thyroid histology: goiter formation, colloid depletion and follicular cell hypertrophy and hyperplasia (35). Treatment with this goitrogen induced significant decreases in thrb, klf9, pcna, mcm2, kif2C, and increased dapl1 transcript abundance in the brain as measured by qPCR (35). ETU treatment also resulted in increased tshb 


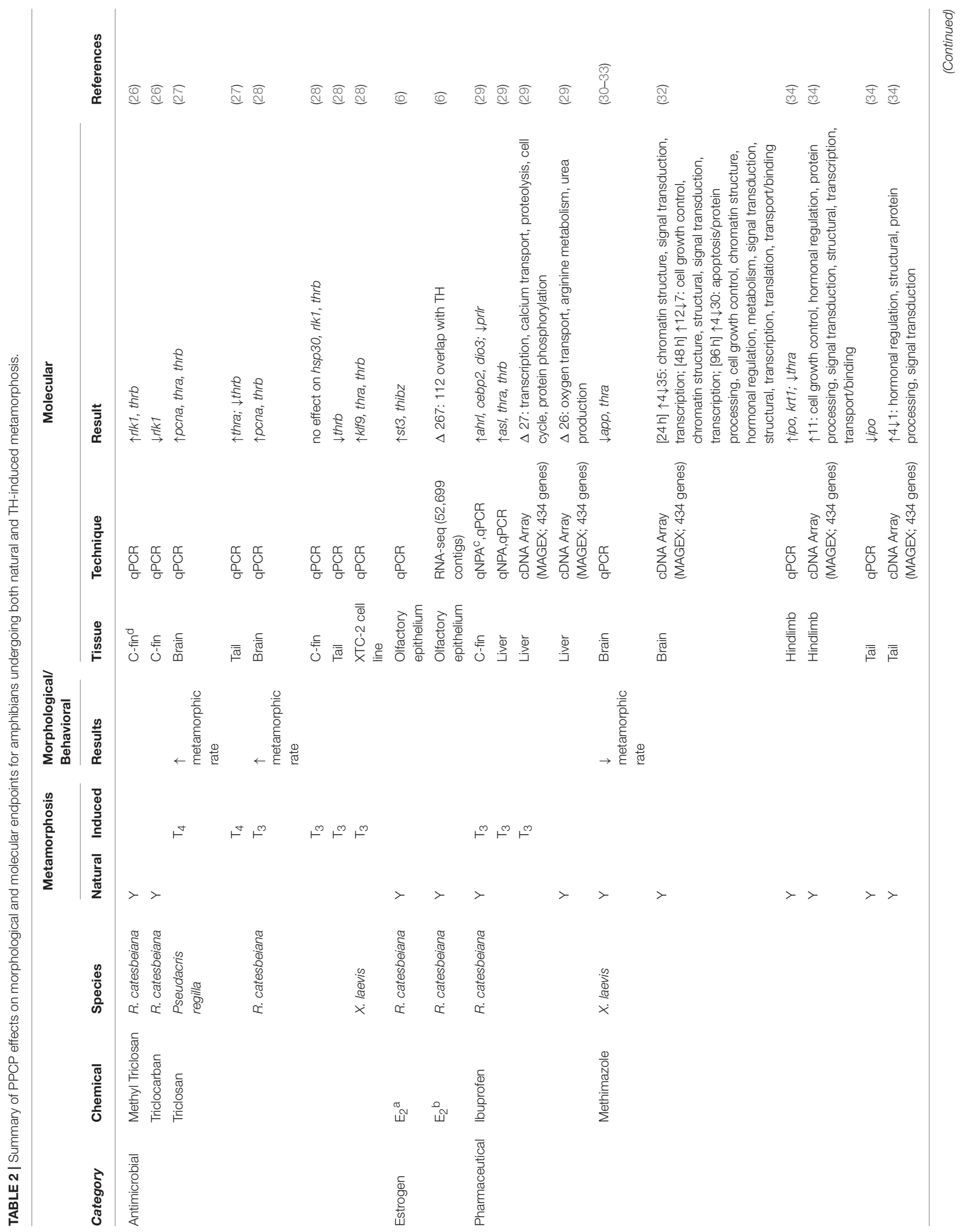




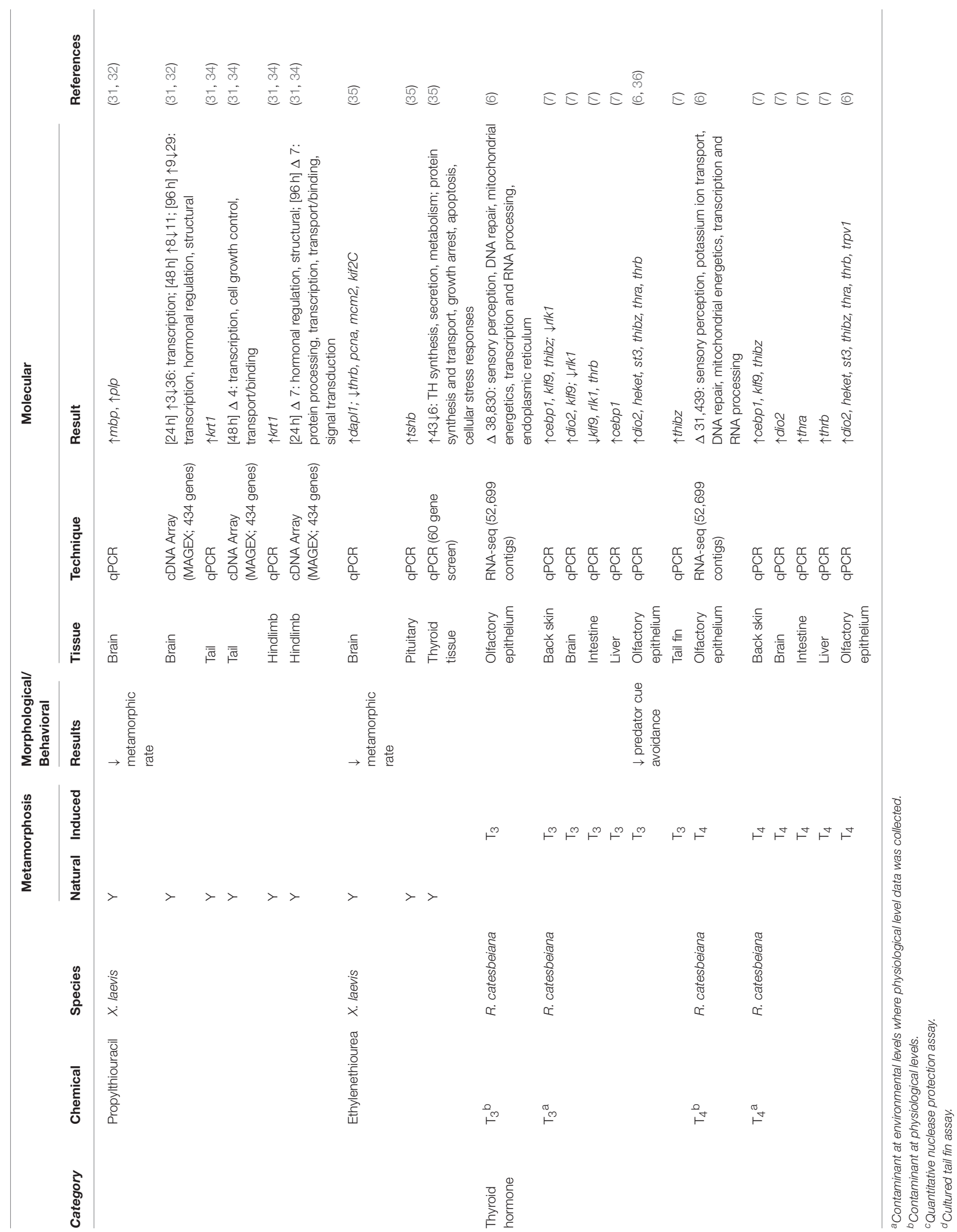


transcripts in the pituitaries. A qPCR candidate biomarker screening was performed on thyroid tissue and 49 of 60 genes had significantly differential abundance following ETU exposure compared to the controls (35). Of these, 43 genes had increased transcript abundance, while six were decreased. These ETUinduced differential transcripts were ontologically associated with the synthesis, secretion, and metabolism of THs, protein synthesis and transport, growth arrest, apoptosis, and cellular stress responses (35).

\section{Methimazole}

Methimazole is an established disruptor of amphibian HPT axis function and has been frequently used as a metamorphosis inhibitor (30). Similar to PTU and ETU, methimazole is a goitrogen and anti-thyroid drug that affects $\mathrm{TH}$ signaling by inhibiting thyroid peroxidase (44). Exposure to methimazole for 14 days during metamorphosis resulted in a significantly decreased metamorphic rate in pre- and prometamorphic $X$. laevis tadpoles and thyroid gland hypertrophy and follicular cell hyperplasia (Table 2) $(30,33)$. The molecular effects of up to $72 \mathrm{~h}$ of methimazole exposure on early prometamorphic $X$. laevis tadpoles were queried by qPCR analysis of known $\mathrm{TH}-$ regulated genes. Zhang et al. found a significant decrease in thra and app gene expression in the brain; a decrease in thra and increase in ipo and krt1 mRNAs in the hindlimb; and a decrease in ipo transcripts in the tail (Table 2) $(36,38,39)$. Helbing et al. used cDNA arrays to further evaluate the pathways affected by methimazole in X. laevis tadpoles (Table 2) (32, 34). In the brain, an increase of 20 and decrease of 76 gene transcripts related to transcription, hormonal regulation, and structural pathways was observed (32). In the hindlimb, the 11 increased transcripts were related to cell growth control, hormonal regulation, protein processing, signal transduction, structural, transcription, and transport/binding pathways. The tail had four increased and one decreased transcript that were related to hormonal regulation, structural, protein processing and signal transduction pathways (34). Ontological analyses of differentially affected brain transcripts were associated with apoptosis/protein processing, cell growth control, chromatin structure, hormonal regulation, metabolism, signal transduction, structural, transcription, translation, and transport/binding pathways with qPCR analysis revealing an increase in ipo and krt1 and a decrease in thra mRNA levels (Table 2) (34).

\section{Estrogen}

The steroid hormone and $\mathrm{TH}$ axes are closely related. As the synthesis of both endocrine hormones is controlled through hypothalamic-pituitary axes and both bind nuclear receptors that stimulate gene expression cascades, it is unsurprising that there is some cross-talk between these two pathways. The majority of studies that have looked at the effects of $17 \beta$-estradiol $\left(\mathrm{E}_{2}\right)$ or the synthetic estrogen $17 \alpha$-ethinylestradiol $\left(\mathrm{EE}_{2}\right)$ on metamorphosis have found a decreased metamorphic rate (Supplementary Table 1) (32-35, 44) [reviewed by Hayes (45)]. However, Frieden \& Naile found accelerated tail reduction in $B u f_{0}\left(B\right.$.) bufo upon exposure to estrone ( $\left.\mathrm{E}_{1}\right)$ (46). How estrogens influence $\mathrm{TH}$ signaling is not completely understood. In adult
R. ridibunda, $\mathrm{E}_{2}$ decreases plasma $\mathrm{T}_{3}$ and $\mathrm{T}_{4}$ (47), although this may not occur during metamorphosis. Brande-Lavridsen et al. found that during metamorphosis in $R$. temporaria, there was no significant difference in total or free $T_{3}$ upon exposure (48). However, Yamauchi et al. found that both $\mathrm{E}_{2}$ and the synthetic estrogen diethylstilbestrol could competitively bind with recombinant $X$. laevis and $R$. catesbeiana transthyretins; TH transporter proteins (49) (Supplementary Table 2). The thyroid itself was found to show no change in number of follicles or overall thyroid volume, although there was a decreased follicular cell height upon exposure to $\mathrm{EE}_{2}$.

To determine the response of the gene program, Jackman et al. investigated the transcriptomic effects of $E_{2}$ in the olfactory epithelium of $R$. catesbeiana and found none of the classic THresponse genes, such as thra, thrb, thibz, or dio2 changed upon an acute exposure to either environmentally-relevant or higher levels of $E_{2}$ (6). This is corroborated by Bulaeva et al. who exposed R. sylvatica to much higher levels of $\mathrm{E}_{2}$ and still saw no significant response of thrb (50). With more in-depth RNA-seq analysis, Jackman et al. found 112 significantly changing contigs that also responded to exposure to $\mathrm{T}_{3}$ and/or $\mathrm{T}_{4}$ (6). However, compared to almost 45,000 contigs that respond to exposure to $\mathrm{TH}$, this cross-talk signaling is quite minimal. As estrogens are found throughout our wastewater systems (51), it is imperative to determine the mechanism by which estrogens are affecting with TH signaling and proper development.

\section{Triclosan and Triclocarban}

Triclosan [5-chloro-2-(2,4-dichlorophenoxy)phenol; TCS] is a bactericidal and antifungal agent that is ubiquitously incorporated into thousands of industrial and consumer products including clothing, toys, cleaning supplies, personal care products (i.e., soap, shampoo, toothpaste, etc.), and surgical soaps and sutures $(52,53)$ with 10.5 million pounds produced globally in 2015 (53). Triclosan and triclocarban (TCC), another widely used antibacterial in PPCPs, are the most common, broad-spectrum antimicrobial agents used in household items and PPCPs (54). While sewage treatment removes most triclosan, it still contaminates sewage effluent and, consequently, aquatic environments (24). The U.S. Food and Drug Administration banned the use of TCS, TCC, and 17 other antimicrobials in personal wash products in 2016 to minimize the exacerbation of bacterial resistance and health risks, including endocrine disruption $(54,55)$. TCS has structural similarity to $\mathrm{TH}$ and disruption of $\mathrm{TH}$ action in frogs provided some of the earliest evidence of this endocrine disruption.

Low and environmentally-relevant amounts of TCS can affect different aspects of TH signaling in amphibians (30, 41, 51-57). Exposure of premetamorphic $R$. catesbeiana tadpoles to environmentally-relevant amounts of triclosan can induce altered growth and transcript responses that are exacerbated upon $\mathrm{T}_{3}$-induced metamorphosis (28). The combinatorial effects of TCS and $\mathrm{T}_{3}$ on tadpoles resulted in greater body mass reductions and precocious metamorphosis. These phenotypic changes were accompanied and preceded by changes to $\mathrm{TH}$ responsive gene expression (28). Expression of thrb was transiently decreased in the tadpole tail at $48 \mathrm{~h}$, while the 
brain had increased expression of thrb and proliferating cell nuclear antigen transcripts (PCNA). Under comparable TCS \pm $\mathrm{T}_{3}$ treatments, cultured $X$. laevis XTC-2 cells had increased expression of thra, thrb, and klf9 after exposure to both chemicals, supporting the developmentally-sensitive TCS effects in different anuran species (28). Recent work demonstrated that $X$. tropicalis exposed to TCS levels considered safe in drinking water developed metabolic pathologies resembling prediabetes and produced progeny exhibiting delayed metamorphosis and diminished reproductive success (58).

Adaptation of the Amphibian Metamorphosis Assay for the Pacific tree frog, Pseudacris (P.) regilla, (TREEMA) revealed comparable morphological and molecular disruption by TCS when administered in conjunction with $\mathrm{T}_{4}$ (27). By the second day of exposure, TCS enhanced the $\mathrm{T}_{4}$-stimulated increases in thra, thrb, and pcna in the tadpole brain and disrupted expression of TH-responsive genes in the tail (Table 2) (27). The earliest morphological effects of TCS and $\mathrm{T}_{4}$ exposures were evident at day 4 with increased foot paddle formation and later impairments in developmental stage progression. Tadpoles exposed to both TCS and $\mathrm{T}_{4}$ also had accelerated development and increased hindlimb length/snout-vent length ratio (27). Like other anurans, the perturbed metamorphic profile in $P$. regilla is indicative of disrupted developmental coordination (27). Exposure of X. laevis tadpoles to TCS resulted in increased thrb mRNA in the tail fin after 21 days followed by thyroid gland hypertrophy at 32 days (Table 2) $(56,57,59,60)$.

Methyl triclosan (mTCS) is a bacterial metabolite of TCS and is more persistent in the environment than TCS, which is readily degraded by photolysis (61). This metabolite, along with TCS and TCC, were tested using premetamorphic $R$. catesbeiana cultured tail fin (C-fin) assays. TCS did not affect TH-responsive $r l k 1$ or thrb transcript abundance, but did increase hsp30 levels (Table 2) (26). mTCS exposure increased both $r l k 1$ and thrb transcripts in the absence of $\mathrm{T}_{3}$ (26), suggesting that some, but not all, of the TCS activity observed in intact animals may be due to the conversion to mTCS. TCC exposure caused a reduction in $r l k 1$ transcripts and an increase in $h s p 30$ mRNA (Table 2) (26), indicating a TH-like activity of this antimicrobial agent.

\section{Ibuprofen}

Ibuprofen is a commonly used non-steroidal anti-inflammatory analgesic that is now a prevalent component of complex municipal wastewater effluents that permeate aquatic environments $(62,63)$. Ibuprofen is primarily considered to act through prostaglandin synthesis inhibition, however, it can also interfere with multiple regulatory pathways $(29,64)$. Little is known about the effects ibuprofen can have on aquatic organisms during sensitive developmental periods, which is concerning given the multiplicity of molecular pathways ibuprofen targets and its abundance in global freshwater environments.

Exposure of $R$. catesbeiana tadpoles to environmentallyrelevant concentrations of ibuprofen disrupted $\mathrm{TH}$-stimulated metamorphic reprogramming of the liver transcriptome and in C-fin assays (Table 2) (29). MAGEX cDNA microarray analyses of tadpole livers exposed to ibuprofen and $T_{3}$ detailed molecular pathways affected by these combined exposures: transcription, calcium transport, proteolysis, cell cycle, and protein phosphorylation. Additionally, ibuprofen treatment affected pathways related to oxygen transport, arginine metabolism and urea production (29). Ibuprofen exposure of $\mathrm{T}_{3}$-stimulated tadpoles enhanced the upregulated expression of thra and thrb. Quantitative nuclease protection assay analysis of C-fin cultures showed that ibuprofen exposure alone could increase expression of dio3, while both ibuprofen and $\mathrm{T}_{3}$ treatment resulted in an increase in $h s p 30$ transcripts, indicating potential tissue-specific responses (29). Ibuprofen can also affect transcriptional programs in the tail fin and back skin of $R$. catesbeiana under temperature-dependent, $\mathrm{T}_{3}$-stimulated conditions and this is further discussed below (65).

\section{INDUSTRIAL AND AGRICULTURAL CHEMICALS}

\section{Polychlorinated Bisphenols (PCBs)}

Polychlorinated bisphenols (PCBs) are ubiquitous environmental contaminants that were widely used in capacitors and transformers between 1929 and 1979 (66). Concern about the endocrine disrupting potential of PCBs resulted in their import and use being banned in North America by 1979. However, the extreme environmental persistence and bioaccumulation of PCBs continue to plague us (66). With the effects of PCBs on $\mathrm{TH}$ homeostasis well-characterized (67), there was a clear need to investigate the effect of these compounds on amphibian metamorphosis.

As the toxicity of PCBs is typically due to bioaccumulation over time, Gutleb et al. examined the effects of ingested PCBs in $R$. temporaria and $X$. laevis after an exposure of either 10 days or several weeks (68). They found that dietary exposure to a technical mixture of PCBs, clophen A50, decreased metamorphic rate in both species after 10 days. Furthermore, exposures to PCB 126 decreased the rate of metamorphosis after several weeks (Supplementary Table 1). In a later study, Gutleb et al. showed that immersion in PCB 77 and apolar sediment extracted from $\mathrm{PCB}$-contaminated ponds significantly reduced the rate of metamorphosis in X. laevis (Supplementary Table 1) (69). Gutleb et al. confirmed these effects using a X. laevis thiourea-synchronized metamorphosis assay and a 60 day dietary exposure. In this study, they found that clophen A50 and an apolar sediment extract from polluted ponds decreased the rate of metamorphosis (Supplementary Table 1) (70).

To assess the effects of PCB exposure on TH-mediated gene expression, Lehigh et al. examined the toxicity of another technical mixture of PCBs, A1254 (71). qPCR analysis of pooled mRNA from $X$. laevis tadpoles showed that A1254 exposures decreased dio 2 and dio 3 expression and increased ttr expression (Table 3). These results, in combination with the previous studies performed by Gutleb et al., show that mixtures of PCBs exhibit significant effects on $\mathrm{TH}$-driven amphibian metamorphosis (Table 3). 


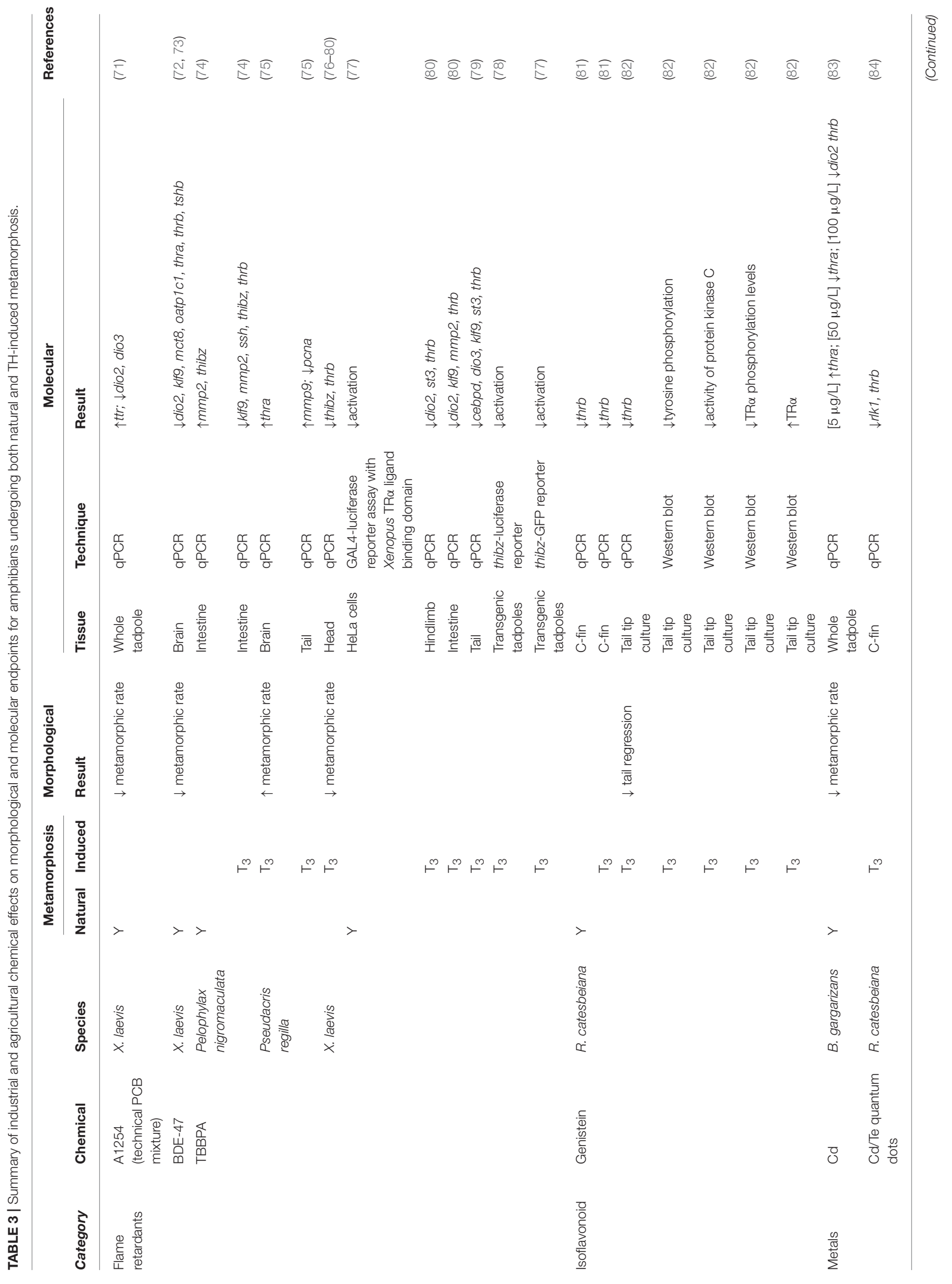




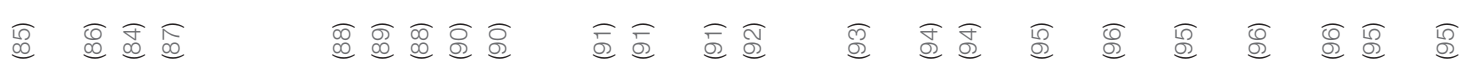

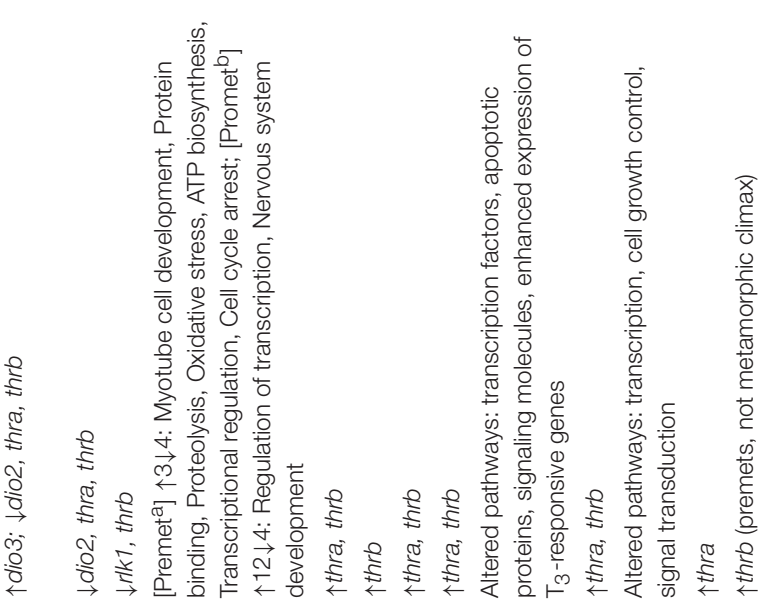

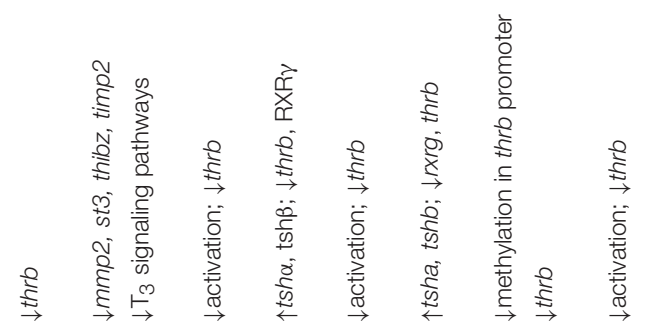
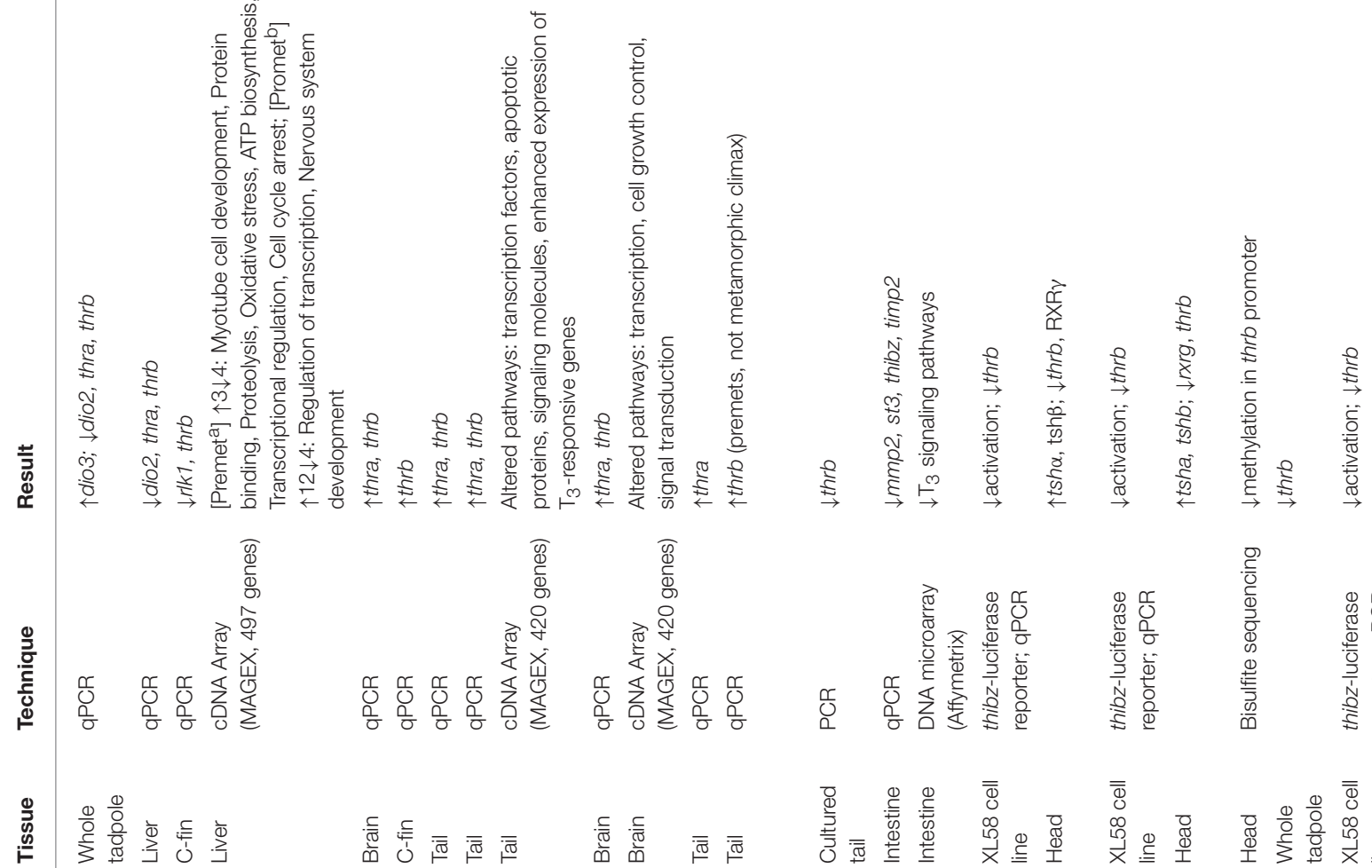

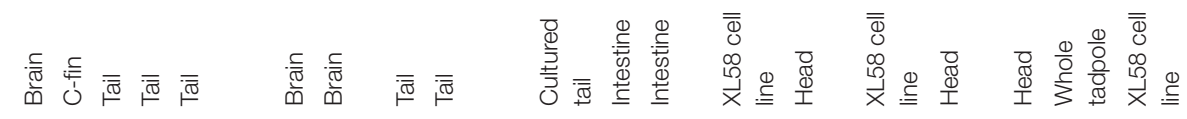
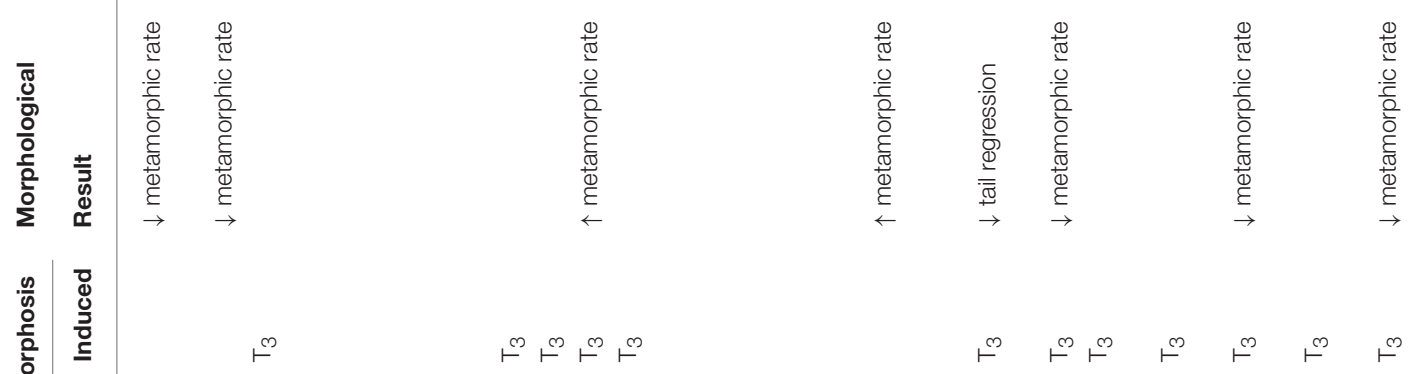

юீトீ

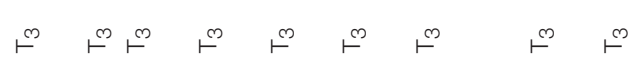

焉
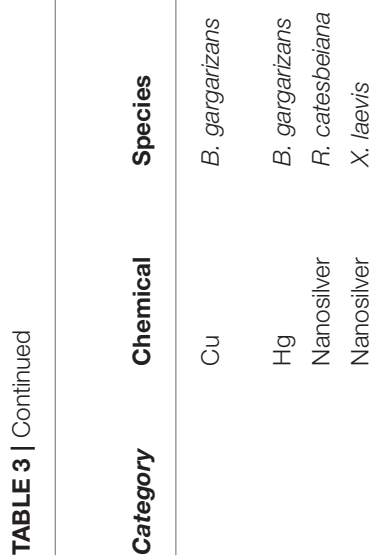

$\frac{1}{0}$
$\frac{0}{0}$
0
0
0
0
0
$\frac{0}{0}$
$\frac{0}{\overline{0}}$
0
0
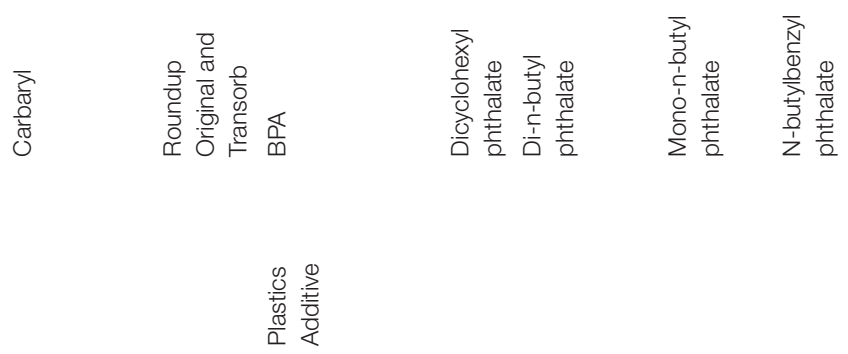

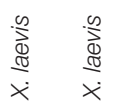

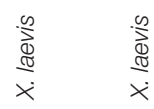
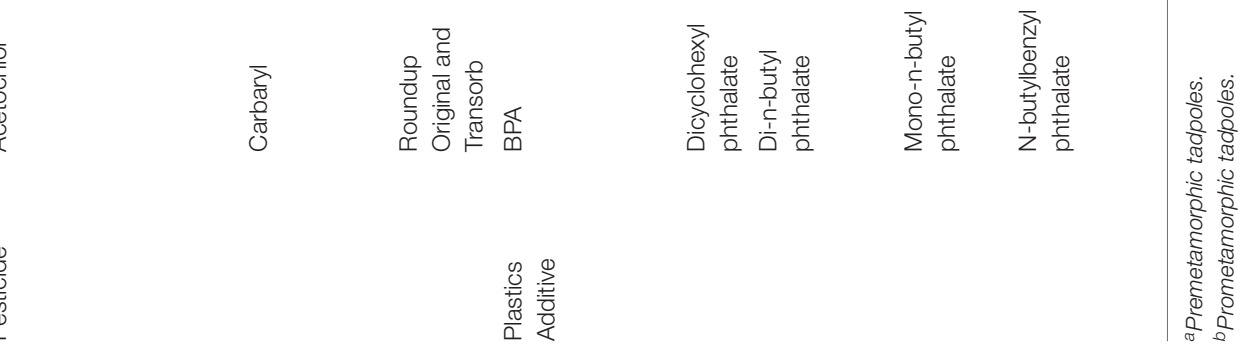


\section{Perchlorate}

Perchlorates, such as ammonium perchlorate, potassium perchlorate, and sodium perchlorate, are well-known as powerful oxidizing agents, which has led to their widespread usage in explosives such as rocket propellants, fireworks, and signal flares (97). They are also used to treat TH diseases (98) as perchlorates competitively inhibit the uptake of iodine by the sodium-iodide symporter, leading to lack of iodine for the production of THs (99). Unfortunately, due to its widespread industrial use, perchlorate is a persistent pollutant. As amphibians have an almost identical TH system to humans, it is unsurprising that perchlorates also affect their $\mathrm{TH}$-regulated processes [reviewed by Carr and Theodrakis (100)], leading to a decreased metamorphic rate $(31,35,50,101-103)$. Chronic exposures to environmental levels of perchlorate decrease $\mathrm{T}_{4}$ in X. laevis, both in vivo (104) and in vitro (105). This indirectly results in the enlargement of the thyroid glands as well as hyperplasia and hypertrophy of thyroid follicles due to the lack of negative regulation of TSH $(20,35,104,106,107)$. Predictably, the decrease in $\mathrm{T}_{4}$ levels also leads to decreased metamorphic rates $(35,101,102,106,107)$.

The involvement of the $\mathrm{TH}$-induced gene expression program in this metamorphic delay seems to be organ-dependent. Using cDNA array analyses of acute exposures of sodium perchlorate in $X$. laevis, Helbing et al. found that the brain was the most responsive with a maximum of 39 responsive genes involved mostly in transcription, transport/binding, apoptosis/protein processing, and structure (Table 3) (32). Tshb mRNA significantly increased after $48 \mathrm{~h}$, suggesting an acute exposure already leads to dysregulation of the negative feedback loop. The cDNA array only indicated 8 and 4 responsive genes in the tail and hindlimb, respectively (34), indicating that these tissues may be less responsive to acute exposures of perchlorate. However, in chronic exposures of environmentallyrelevant levels of perchlorate, there is a more consistent response. Flood \& Langlois (108) observed decreased TH-responsive genes, thra, and thrb, in the liver of $X$. tropicalis chronically exposed to potassium perchlorate. A similar result was seen in the brain of X. laevis chronically exposed to sodium perchlorate (Table 3) (35). Bulaeva et al. (50) found that $R$. sylvatica had decreased thrb transcript levels in the tail and liver, which could be continually observed even 40 days after a 2 week exposure to sodium perchlorate, indicating that the effects from perchlorate may be persistent and possibly irreversible.

\section{Brominated Flame Retardants (BFRs)}

Brominated flame retardants (BFRs) have been and continue to be ubiquitously incorporated into a variety of items to confer fire resistance (109). These materials include textiles, plastics, electronic circuitry, wood, paper, dust, and inadvertently in the 1970's, livestock feed (109-111). Roughly 5,000,000 metric tons of bromine are produced worldwide annually, with demand increasing each successive year (111). BFRs include polybrominated diphenyl ethers (PBDEs), polybrominated biphenyls (PBBs), tetrabromobisphenol A (TBBPA) and hexabromocyclododecane (HBCD). Depending upon the mechanism by which BFRs are integrated within materials,
BFRs can be classified as brominated monomers, reactive (i.e., TBBPA) or additive (i.e., PBDE, HBCD). BFRs can readily leach from materials if they are not strongly chemically bound to the composite polymer, thereby contaminating the environmental biota, leading to mortality, compromised development and other toxicity-dependent pathologies among animal populations. A growing concern is that increasing amounts of BFRs have been found in the environment throughout different trophic levels, including humans, underscoring the need to better understand the biological implications of BFRs (111). Many BFRs are lipophilic and this facilitates their persistent bioaccumulation in the biota of both aquatic and terrestrial environments (112). Due to the deleterious effects of penta- and octa-BDE BFRs and $\mathrm{PBBs}$, they have since been banned, which has spurred the development of novel BFRs (111). However, the environmental effects of these novel BFRs, which are not limited to TBBPA derivatives, are under increasing scrutiny (110, 113). Herein, we review BFRs that have a demonstrated effect on amphibian metamorphosis (Table 3).

\section{Polybrominated Diphenyl Ethers (PBDE)}

PBDEs are widely disseminated throughout invertebrates, vertebrates, sediments, and diverse environments, including Arctic marine biota (72). PBDEs can readily accumulate and magnify within trophic levels (114). Mammalian biotransformation of PBDEs to hydroxylated metabolites by cytochrome $\mathrm{P} 450$ enzymes result in products that are more toxic than the parent congeners. As previously reviewed, these metabolites can disrupt thyroid homeostasis via several mechanisms including: decreased free and total $\mathrm{TH}$ through the competitive binding of thyroid transport proteins and perturbed $\mathrm{TH}$ metabolism through glucuronidation, sulfation, and deiodination (72). Notably, there are strong structural similarities between THs and PBDEs.

$X$. laevis tadpoles (NF stage 50) fed 1,000 or $5,000 \mu \mathrm{g} / \mathrm{g}$ of a commercial mix of PBDE congeners, DE-71, exhibited significant inhibition of metamorphosis as displayed by delayed limb development and tail resorption, lack of pigmentation and head shape changes (72). No major cellular or morphological differences of the thyroid gland were observed following histological analyses. Intraperitoneal injections of DE-71 and BDE-47, but not BDE-99, resulted in delayed metamorphosis through significant reductions in tail resorption (72). Both BDE47 and BDE-99 are major congeners of DE-71. Although the morphological results of this study implied the disruption of $\mathrm{TH}$ activity, such involvement could not be conclusively ascertained.

$R$. pipiens tadpoles fed lower, environmentally relevant amounts of DE-71 at Gosner stage 25 to stage 42 had delayed metamorphic climax by $22-36$ days $(3,115)$. The elimination of PDBEs following depuration was studied in $R$. pipiens tadpoles that had consumed environmentally-relevant concentrations of DE-71 for 50 days at Gosner stage 25. Following 28 days of depuration, tadpoles had removed more than $94 \%$ of PBDE congeners from their bodies (114). The ability to eliminate PBDEs from tissues can vary according to life stage. Metamorphosing frogs (Gosner stage 42-46) were unable to eliminate PBDEs following depuration, however, juvenile frogs 
eliminated $89.7 \%$ of PBDEs over a 70 day depuration (114). Wild $R$. limnocharis adult frogs found proximal to contaminated e-waste recycling sites similarly showed reduced PBDE levels following 54 days of depuration (116).

A link between PDBE-altered amphibian metamorphic morphology and disrupted TH metabolism was demonstrated by the treatment of $X$. laevis tadpoles with increasing concentrations of BDE-47 (73). After a 21 day BDE-47 dietary exposure, tadpoles exhibited reduced developmental stage progression and decreased hindlimb length. Histological analysis of the thyroid gland showed decreased follicular epithelial cell height and a smaller thyroid lobe area in tadpoles exposed to BDE-47 (73). Corresponding reductions in hindlimb length were observed in $X$. tropicalis tadpoles following BDE-47 exposure (117). BDE-99 exposure in $X$. tropicalis similarly resulted in slower developmental stage progression and reduced hindlimb length (117). qPCR analyses in X. laevis to assess transcriptomic changes in the tails and livers of stage-matched tadpoles between NF stage 52 to 56 found tissue-specific $\mathrm{TH}$-dependent regulation (73). No significant differences were observed in tail thra, thrb, dio1, or dio 2 transcripts. However, the brain was sensitive to BDE-47 treatment and significant reductions were observed in thra, thrb, klf9, tshb, dio2, mct8, and oatp1c1 mRNA (73). The diversity of affected transcripts underscores the broad extent to which thyroid metabolism is adversely affected by BDE- 47 .

\section{Tetrabromobisphenol A (TBBPA)}

Tetrabromobisphenol A $\left(2,2^{\prime}, 6,6^{\prime}\right.$-tetrabromo-4, $4^{\prime}$ isopropylidenediphenol; TBBPA) is one of the most abundantly used BFRs, with 150,000 metric tons produced each year. Although the majority of TBBPA is covalently bound within polymer materials, $\sim 10-20 \%$ can leach into the proximal environment $(118,119)$. As such, TBBPA is found dispersed within environments around the world and in the tissues of affected organisms $(112,119)$. TBBPA was introduced as a replacement for PBDEs, in part due to their comparatively short half-life in mammals (120). However, TBBPA has been detected in environmental samples and humans, including breast milk (121). TBBPA bears structural similarity to $\mathrm{T}_{4}$ and binds to human transthyretin more strongly than $\mathrm{T}_{4}$ (122), but is weak competitor to $\mathrm{T}_{3}$ for binding $\mathrm{TR} \alpha$ in rat (123). TBBPA is also reported to disrupt $\mathrm{T}_{3}$ binding to TRs in rat (123).

TBBPA antagonizes tail resorption during $\mathrm{TH}$-mediated metamorphosis in the wrinkled frog, R. rugosa, and the $\mathrm{T}_{3}$ associated gene expression of thrb and thibz in X. laevis $(76,123)$. TBBPA can also act as a TH agonist during metamorphosis in $P$. regilla (75). These contradictory findings may reflect unique endocrine sensitivities due to differential anuran metamorphic trajectories (124). P. regilla tadpoles (Gosner stages 30-31) exposed to $10 \mathrm{nM}$ TBBPA had increased tail regression and mmp9 expression following $\mathrm{T}_{3}$-induced metamorphosis. MMP9 is a metalloproteinase involved in the deconstruction of the extracellular matrix and is required for tail resorption (125). Following $100 \mathrm{nM}$ TBBPA exposure in the context of $\mathrm{T}_{3}$ stimulated metamorphosis, thra mRNAs were significantly increased in the brain relative to TBBPA exposure alone while the abundance of pcna transcripts was decreased in the tail (75).
Fini et al. demonstrated that $X$. laevis tadpoles (NF stage 45) can rapidly take up radiolabeled TBBPA and retain the parent TBBPA and its biotransformed metabolites (TBBPAglucuronide, TBBPA-sulfate, TBBA-glucuronide-sulfate), while only gradually releasing them (77). TBBPA was shown to be the principal agent of antithyroidal activity, not its biotransformed congeners. TBBPA, but not its metabolites, impaired $\mathrm{T}_{3}$-induced regression in tadpole head size and gills (77). Moreover, by using transgenic tadpoles containing a thibz promoter-green fluorescent protein (thibz-GFP) TH-response reporter construct, $10 \mu \mathrm{M}$ TBBPA, not its sulfate conjugates, inhibited $\mathrm{T}_{3}$-induced GFP expression (77). TH metabolizing enzymes, deiodinases, UDP-glucuronyl transferases and sulfotransferases were not affected by TBBPA with or without $\mathrm{T}_{3}$ induction. A GAL4luciferase reporter assay using the Xenopus TR $\alpha$ ligand binding domain transiently transfected into HeLa cells demonstrated that TBBPA can effectively compete with $\mathrm{T}_{3}$ binding. However, sulfated TBBPA conjugates lack this $\mathrm{T}_{3}$ displacement capacity (77). Independent studies in $X$. laevis recapitulated similar finding of TBBPA inhibition of $\mathrm{T}_{3}$-mediated reductions in head area, hindlimb length and decreased apoptosis and epithelial folds within intestines (78-80). Additionally, various groups described the restricted activation of a thibz response element-luciferase reporter assay and the reduction of tissuespecific gene expression of thrb, st3, klf9, cebpd, mmp2, dio2, and dio3 transcripts upon TBBPA inhibition of $\mathrm{T}_{3}$-induced metamorphosis (Table 3) (78-80).

TBBPA is proposed to have developmental stage-specific effects on $X$. laevis metamorphosis, potentially related to endogenous levels of TH. During pre- and prometamorphosis, endogenous levels of $\mathrm{TH}$ are low and TBBPA exposure was associated with increased hindlimb length and the promotion of development. However, during metamorphic climax when $\mathrm{TH}$ amounts are maximal, developmental stage transitions were delayed (80). An additional potential confounder may be the amount of TBBPA that metamorphic anurans are exposed to (74). Molecular analysis of Pelophylax (P.) nigromaculatus intestines showed that tadpoles exposed to low concentrations of TBBPA ( $1 \mathrm{nM}$ ) had agonistic effects on $\mathrm{T}_{3}$-induced expression of TH-response genes (Table 3). In contrast, higher TBBPA concentrations (100-1,000 nM) had antagonistic effects in the same experimental paradigm (74). The molecular mechanisms by which TBBPA may act as both an agonist and antagonist of tissuespecific development while endogenous TH levels vary need to be ascertained.

\section{Bisphenol A (BPA)}

Bisphenol A $\left(4,4^{\prime}\right.$ isopropylidenediphenol; BPA) is a widely used monomer in the manufacture of polycarbonate plastics, epoxy resins and food containers. More than 2.2 million metric tons of BPA were globally produced in 2009. Since the 1930's, BPA was known to be xenoestrogenic and growing concerns about the exposure of humans to BPA culminated in the US Food and Drug Administration banning BPA from baby bottles in 2012 (126). Despite debates between food and drug administrations and researchers about the endocrine disrupting effects of BPA, this monomer has been implicated in a plethora of etiologies 
including diabetes, obesity, and hypothalamic neuroendocrine dysfunction. Early developmental periods are also ostensibly sensitive to the effects of BPA (127-129).

BPA is found ubiquitously throughout the environment, soils, surface waters, sewage, and more. Detoxification of BPA within organisms occurs through glucuronidation and the biotransformed oxidative metabolites that result can have greater endocrine disrupting effects than the parent BPA or analog (130). While the effects of BPA on estrogenic dysregulation are well-studied, BPA can also affect signaling pathways of THs, androgens, and glucocorticoids (130). BPA exposure inhibits amphibian metamorphosis by targeting $\mathrm{TH}$ signaling and is extensively reviewed in Heimeier and Shi (131).

$X$. laevis embryos exposed to BPA displayed delayed metamorphosis by 2-4 stages at NF stages 52-54 (Table 3) (93). Tadpoles exposed to BPA had similarly delayed natural and $\mathrm{T}_{4}$-induced metamorphosis. Cultured tadpole tails treated with BPA had repressed $\mathrm{T}_{3}$-induced tail shortening and had BPAinhibited thrb expression in the presence and absence of $\mathrm{T}_{4}$ stimulation (93).

Twenty-one day exposure of $X$. laevis tadpoles to BPA concentrations that were equivalent to human infant exposures also protracted $\mathrm{T}_{3}$-induced metamorphosis by 8 stages and stalled intestinal development (Table 3) (94). By 4 days, however, maladaptive molecular effects were observed in the reduced expression of early $\mathrm{T}_{3}$-responsive genes, st 3 and thibz, and the late responders, $m m p 2$ and timp2, in the intestine following combined $\mathrm{BPA}$ and $\mathrm{T}_{3}$ exposures. An oligo DNA microarray analysis of the intestinal transcriptome confirmed that BPA antagonizes the expression of genes involved in $\mathrm{T}_{3}$ signaling pathways (Table 3) (94).

\section{Genistein}

Genistein is a plant-synthesized isoflavinoid found in high amounts in soy products (132). As a phytoestrogen, the endocrine disrupting capabilities of this compound have been well-studied for estrogen signaling [reviewed by Henley and Korach (133)]. However, its effects on TH signaling have been far less studied. Ji et al. acutely exposed premetamorphic $R$. catesbeiana tadpoles to $T_{3}$ and then cultured the tail tips in the presence or absence of genistein to determine the effects of this contaminant on THinduced metamorphic changes (82). Exposure to genistein led to the ablation of tail tip regression seen upon exposure to only $\mathrm{T}_{3}$. This morphological response is correlated with a decreased abundance of the thrb transcript (Table 3). In support of this finding, Hinther et al. also found decreased thrb upon exposure of cultured tail fin of $R$. catesbeiana to genistein, both induced and not induced by $\mathrm{T}_{3}$ (Table 3) (81). A possible mechanism by which TH signaling is being disturbed is through modulation of phosphorylation pathways. Genistein is a tyrosine protein kinase inhibitor (134), which is demonstrated in this amphibian model by leading to reduced overall tyrosine phosphorylation in $\mathrm{T}_{3}$ exposed R. catesbeiana tail tips cultured with genistein (82). As tyrosine phosphorylation of protein kinase $\mathrm{C}$ (PKC) is known to increase the activity of this kinase (135), the decreased tyrosine phosphorylation induced by genistein is correlated with negative
PKC activity. It is postulated that this phosphorylation pathway impacts $\mathrm{TH}$ signaling through PKC serine phosphorylation of $T R \alpha$. Upon acute exposure to $T_{3}$, there is a significant increase in serine phosphorylation in $R$. catesbeiana tail tips, which can be reversed with PKC inhibitors (82). This response is attenuated by exposure to genistein, which likely leads to the observed decrease in the TH response gene thrb. Genistein can also affect thyroid peroxidase function in mammalian systems [reviewed by Doerge and Sheehan (136)]; however, whether this affects TH signaling in amphibians has yet to be determined. Further studies are needed to determine the role of phosphorylation pathways in cellular level TH signaling and whether other areas of the greater TH signaling pathway are affected by this contaminant.

\section{Phthalates}

Phthalates are plasticizers added to increase the flexibility of plastics. These contaminants can be found in the air, soil, freshwater, and saltwater (137-139). The ubiquity of phthalates in the environment is concerning as they have shown to have $\mathrm{TH}$ disrupting effects [reviewed by Mathieu-Denoncourt et al. (140)]. Using a $\mathrm{T}_{3}$-activated $X$. laevis reporter cell system (Table 3 ), Sugiyama looked at the effects of five different phthalates on $\mathrm{T}_{3}$ signaling within the constructed cells (Table 3 ) and found di-n-butyl phthalate, n-butylbenzyl phthalate and dicyclohexyl phthalate caused a decrease in activity (95). These TH-disrupted responses were all associated with a decrease in endogenous thrb mRNAs in the reporter cells. N-butylbenzyl phthalate also led to decreased thrb with a $\mathrm{T}_{3}$-induced whole tadpole exposure. In line with these findings, Shen et al. found that chronic exposure of $X$. laevis tadpoles to di-n-butyl phthalate and its metabolite mono-n-butyl phthalate resulted in decreased thrb (96).

The mechanism by which phthalates disrupt TH signaling within the cell likely involves the regulation of TRs. Using a TR-mediated reporter gene assay, Shen et al. found that dibutyl phthalate, mono-n-butyl phthalate, and di-2-ethylhexyl phthalate demonstrated TR $\beta$ agonist activity (141). As TRs have various methods by which they can be regulated, Shen et al. queried the involvement of the TR corepressor silencing mediator for retinoid or TH receptors (SMRT) in the phthalate-dependent TR regulation and found that both di-n-butyl phthalate and mono-n-butyl phthalate increased the interaction between SMRT and TR in a mammalian two-hybrid assay (Table 3) (96). Furthermore, in the amphibian system, decreased methylation of the promoter region of thrb was found upon exposure to monon-butyl phthalate, which could be involved in TR-mediated regulation of the thrb gene. However, the same result was not seen with di-n-butyl phthalate, indicating potential differences in phthalate response (96). The involvement of other epigenetic mechanisms, such as histone post-translational modification, has yet to be elucidated. In contrast to the aforementioned studies, Mathieu-Denoncourt found that chronic exposure to monomethyl phthalate, a dimethyl phthalate metabolite, led to an increased metamorphic rate in $X$. tropicalis that associated with no $\mathrm{TH}$ response gene expression changes (Supplementary Table 1) (142). This suggests that various phthalates may have different mechanisms of disruption and/or 
the timing of $\mathrm{TH}$ response gene effects have differing response kinetics that were not captured in the study. Further work on these substances on a broader range of amphibian species is warranted.

\section{Metals}

Metals acting as environmental contaminants stem from a variety of natural and anthropogenic sources (143). Heavy metals are notable environmental endocrine disrupting chemicals (EDCs) and can dysregulate TH-driven amphibian metamorphosis upon exposure.

Cadmium (Cd) exposure has been shown to significantly decrease metamorphosis in B. americana (144), as well as completely block completion of metamorphosis in other amphibians like Pleurodeles walt (145). There is a significant correlation between $\mathrm{Cd}$ concentration and decreasing rates of metamorphosis in X. laevis (146). Furthermore, the effects of Cd exposure are exacerbated in male $X$. laevis tadpoles when the environmental pollutant estradiol-17 $\beta\left(\mathrm{E}_{2}\right)$ is present (147).

Sun et al. observed significant decreases in dio2, thra, and thrb transcripts following Cd exposures in B. gargarizans at concentrations an order of magnitude lower than previously reported to decrease metamorphic rate (83). At the lowest $\mathrm{Cd}$ concentration, an increase in thra expression was observed, but this may be due to using $a c t b$ as a single normalizer, which can be TH-responsive (87). Thyroid histology revealed significant follicular cell hyperplasia in the cadmium-exposed animals.

Copper is naturally ubiquitous in the environment and influxes of anthropogenic copper occur due to soil disturbances or agricultural runoff (148). In several Ranidae species and $B$. gargarizans, chronic exposure to copper can significantly delay the rate of metamorphosis (Table 3) $(85,148,149)$. Wang et al. showed that copper exposure in $B$. gargarizans significantly increased dio3 expression and significantly decreased dio2, thra, and thrb expression at copper concentrations greater than what caused metamorphic delay (85). Although a transcriptional response is expected at lower concentrations, it is possible that measurements were done too late to observe significant changes in TH-related transcription as tadpole exposures commenced at Gosner stage 26 and transcript quantification did not occur until stages 42 and 46. Copper exposure also induced follicular cell hyperplasia in the thyroid gland.

Chronic mercury exposure exhibited a similar phenomenon in B. gargarizans as did copper; metamorphosis was delayed at lower concentrations than what caused significant decreases in dio2, thra, and thrb expression and induced follicular cell deformation in the thyroid gland (Table 3) (86). Again, transcript measurements were performed much later than the initial exposure such that lower concentration transcript effects may have been missed.

Other metals that resulted in a delay in metamorphosis include lead $(\mathrm{Pb})$ in $R$. pipiens (Table 3), iron (Fe; ionized or ore particulates) or manganese $(\mathrm{Mn})$ in $R$. catesbeiana, and depleted uranium (U) in X. laevis tadpoles (Table 3 and Supplementary Table 1) and further research on their effects on TH signaling is needed (150-152).

\section{Nanoparticles}

Several metals have been manufactured as constituents of nanoparticles. Nanoparticles are any particles that have at least one dimension $<100 \mathrm{~nm}$ (153). These nanoparticles possess unique properties compared to their ionic counterparts that make them highly desirable for wide use in industrial and medical applications. However, this has led to significant environmental contamination by nanoparticles and the endocrine disrupting potential of nanoparticles has been well-documented (153). As nanoparticles have unique aggregation and surface charge distributions, their exposure often results in different endocrine disrupting effects compared to their corresponding metal ions (154). It is important to study the endocrine disrupting potential of metal ions and nanoparticles separately as the effects of one are not necessarily predictive of the other. Nevertheless, few studies directly compare the effects of nanoparticle and metal ion exposures in the same study. Further complications in comparing the effects of nanoparticle and constituent ion exposures arise from differences in experimental conditions and species studied.

Chronic exposure to zinc, copper, and titanium oxide nanoparticles can delay metamorphosis in $X$. laevis tadpoles (155-158). However, titanium oxide-based nanoparticles or their ionic counterparts had no effect on $\mathrm{TH}$ signaling in the $R$. catesbeiana C-fin assay (159). Nanoparticle interference significantly decreased the rate of metamorphosis in $R$. sylvatica tadpoles chronically exposed to nanogold (Supplementary Table 1) (160).

Specific gene targets of nanoparticle endocrine disruption were investigated by Hinther et al. using a $R$. catesbeiana C-fin assay and $48 \mathrm{~h}$ exposures (84). They found that exposure to silver nanoparticles or Cd telluride quantum dots in combination with $\mathrm{T}_{3}$ significantly decreased the expression of the $\mathrm{TH}$-responsive genes: $r l k 1$ and thrb (Table 3). The extent of TH-mediated gene disruption arising from 28 day nanosilver exposures was further evaluated by Carew et al. in pre- and prometamorphic $X$. laevis tadpoles (87). They found that, while exposure did not alter the overall rate of metamorphosis, there were transient perturbations of leg length and snout/vent length that were pre- or prometamorph-specific. Using a MAGEX cDNA array and qPCR performed on liver tissue extracted from these tadpoles, they identified 3 induced and 4 repressed transcripts in premetamorphs and 12 induced and 4 repressed transcripts in prometamorphs exposed to nanosilver (Table 3) (87). Of these, mmp9, pparg, and trip4 have linkages to TH signaling pathways.

\section{Pesticides}

\section{Acetochlor}

Acetochlor

[2-chloro- $N$-(ethoxy-methyl)-N-(2-ethyl-6methylphenyl) acetamide] is a widely used preemergent herbicide and persistent organic pollutant that contaminates groundwater (161). More than 10 million $\mathrm{kg}$ of acetochlor are used per year in the United States, with surface water concentrations ranging from median levels of $2.7 \mathrm{nM}$ (730 $\mathrm{ng} / \mathrm{L})$ to as high as $10 \mathrm{nM}(2.7 \mu \mathrm{g} / \mathrm{L})$ within the 80 th percentile of measurements sampled in the Midwestern United States (162, 163). Acetochlor can induce TH-dependent dysfunction and other pathologies in a variety of aquatic species (164-167). 
In combination with other pesticides, acetochlor may contribute to altered comorbid fungal infections in amphibians (168).

Concurrent treatment of premetamorphic $R$. pipiens tadpoles with acetochlor and $\mathrm{T}_{3}$ resulted in the acceleration of metamorphosis as evidenced by precocious forelimb emergence (169). As priming tadpoles with $\mathrm{T}_{3}$ prior to acetochlor treatment did not cause accelerated metamorphosis, it was concluded that acetochlor was interacting with $\mathrm{T}_{3}$ in a TR-independent manner to elicit precocious development (169).

$R$. catesbeiana tadpoles exposed to environmentally relevant concentrations of acetochlor $(10 \mathrm{nM})$ did not affect thrb expression in tail fin biopsies (89). However, the combined treatment of acetochlor with $\mathrm{T}_{3}$ caused a synergistic increase in thrb, which concurred with earlier morphological findings of accelerated metamorphosis (89). Acetochlor induced the upregulation of thra and thrb in the brains of athyroid premetamorphic $R$. catesbeiana tadpoles and these increases were amplified upon exogenous $\mathrm{T}_{3}$ treatment (88). These results suggest a tissue-specific sensitivity to acetochlor. The thra/thrb transcript ratios were also altered and these transcript changes were not associated with any effects on escape behavior following acetochlor treatment (88).

Understanding of the TH-dependent molecular mechanisms disrupted by acetochlor was refined by cDNA microarray studies in X. laevis. Crump et al. demonstrated that changes in gene expression precede the morphological changes of $\mathrm{T}_{3}$ induced accelerated metamorphosis ensuing from acute and environmentally-relevant acetochlor exposures (90). After $48 \mathrm{~h}$, acetochlor exposure caused a $\mathrm{T}_{3}$-mediated increase in thra and thrb and the overall magnification of genes otherwise upregulated by $\mathrm{T}_{3}$ (90). Of interest is that genes normally downregulated by $\mathrm{T}_{3}$ showed an attenuated response in the presence of acetochlor, suggesting that acetochlor perturbs mechanisms of transcriptional regulation (Table 3). Such impairment of transcription implies that acetochlor may disrupt epigenetic modes of regulation (90).

During prometamorphosis, endogenous levels of TH naturally increase and acetochlor exposure caused an accumulation of thra and thrb transcripts in tail fin biopsies from $R$. catesbeiana tadpoles. The brains of these acetochlor-treated prometamorphic tadpoles were assessed after a 59 day depuration period and no significant differences were observed in thra and thrb transcripts, although the ratios between them were altered at higher acetochlor concentrations (88). No major developmental changes were observed either in forelimb emergence, tail regression or mouth development (88).

\section{Carbaryl}

Carbaryl belongs to the carbamate class of insecticides and is commonly used in agricultural and home garden applications to control insect populations (170). Though presumed to have low toxicity, carbamates have structural similarities to organophosphate insecticides and can modify acetylcholinesterases, which has important implications for neurotransmission $(171,172)$. Carbaryl exposure can limit the resistance of amphibians to parasitic infection and its toxicity is exacerbated by previous Ranavirus infection of $R$. sylvatica
$(173,174)$. Of outstanding interest are the implications for metamorphosing organisms in carbaryl-treated areas.

$R$. clamitans tadpoles exposed to environmentally relevant carbaryl concentrations did not have altered metamorphosis according to morphological metrics: tadpole development and time to metamorphosis $(91,175)$. However, both short- and longterm alterations in gene expression were observed in brain and tail tissues of tadpoles acutely exposed to carbaryl at 8 and 16 weeks post-hatching (Table 3) (91). Gosner stage 25 tadpoles exposed to carbaryl for 3 days at 16 weeks post-hatching had higher thra and thrb expression in the brain at Gosner stage 46. Greater thrb expression was also observed in tadpoles exposed at 8 weeks post-hatching (91). DNA microarray analysis highlighted the persistent transcript effects of carbaryl on altered brain pathways that included transcription, signal transduction and cell growth control. Immediately following carbaryl exposure, thra is increased in the tadpole tail (91). Pesticide exposures during such sensitive early developmental periods have potential consequences for fitness and health of the organism during its lifespan.

\section{Glyphosate and Surfactants}

Glyphosate is a commonly used herbicide for both domestic and agriculture applications around the world. Many commercially available formulations, such as Roundup ${ }^{\circledR}$, contain glyphosate, which is rendered more toxic due to the inclusion of surfactants, whose toxicity can be influenced by $\mathrm{pH}$, temperature, and species and developmental stage of exposed organisms $(176,177)$.

Several North American amphibians (R. clamitans, R. pipiens, $R$. sylvatica, and B. americana) exposed to glyphosate, different commercial herbicides and the surfactant polyethoxylated tallowamine (POEA) exhibited varying sensitivities depending on developmental stage and species (92). Glyphosate alone did not elicit deleterious effects, but in combination with POEA in Roundup Original ${ }^{\circledR}$ and Roundup Transorb ${ }^{\circledR}$, metamorphic defects were observed, particularly in $R$. pipiens, which was sensitive to these exposures (Table 3). Consequent to exposures at Gosner stage 25, tadpoles exhibited increased time to metamorphosis. Gonadal abnormalities were also observed as was tail damage that included necrosis, blistering, and abnormal growth (92). As observed with other disruptions to $\mathrm{TH}$ signaling, molecular aberrations were observed prior to phenotypic changes. At stage 25 , but not 42 , increases in thrb expression resulted from exposure to Roundup Original ${ }^{\circledR}$ and Roundup Transorb ${ }^{\circledR}$ (92). However, newer glyphosate herbicide formulations that do not include POEA are less toxic, making them more promising potential alternatives for agricultural and domestic use.

\section{COMPLEX MIXTURES}

Although there is considerable focus on the effects of individual toxicants on TH activity, such chemicals do not persist alone in the environment. Mixture effects arising from the combination of different toxicants can result in $\mathrm{TH}$-dependent disruptions not predicted by the individual chemical constituents (178). 


\section{Metal Mixtures}

Heavy metals exhibit increased toxicity as a consequence of mixture effects (179). Dorchin and Shanas examined the endocrine disrupting potential of a mixture of metals $(\mathrm{Cu}, \mathrm{Pb}$, and $\mathrm{Ni}$ ) in concentrations comparable to that of runoff from busy highways (180). Exposure to this metal mixture significantly decreased the metamorphic rate of Bufo (B.) viridis tadpoles (Table 4) (180). A similar effect of metal mixtures was observed in Limnodynastes peronei, which exhibited a decreased rate in metamorphosis after being exposed to coal-mine wastewater containing low metal amounts (Table 4) (185).

\section{Wastewater Effluents}

Wastewater effluents (WWE) are complex mixtures that can contain contaminants from agricultural, industrial, and domestic sources and hence, can disrupt $\mathrm{TH}$ function. A primary source of contamination comes from PPCPs in human waste. Although wastewater goes through extensive filtration prior to dispersal, $\mathrm{TH}$ disruption still ensues from effluent exposures (36). The TH disruption potential of WWE was first examined in 2009 when Sowers et al. found that a $50 \%$ dilution of municipal WWE significantly decreased the rate of $R$. pipiens metamorphosis (Table 4) (186). A delay in metamorphosis was also observed in $R$. catesbeiana after exposure to pond water that had been a receptacle for municipal WWE (Table 4) (187).

Searcy et al. examined the effects on TH-mediated metamorphic gene expression within $X$. laevis tadpole ex vivo tail tip cultures exposed to WWE (184). Using oligo microarray and qPCR analyses, they found that WWE and $\mathrm{T}_{3}$ exposures significantly increased the expression of $\mathrm{TH}$-sensitive genes: thrb, dio2, crhbp, and fap (Table 4). The in vivo effects of WWE on TH-linked gene expression was also demonstrated by Castillo et al. in a transgenic X. laevis harboring a thibzGFP reporter construct that was activated by WWE exposure (Table 4) (188).

As wastewater treatments do not completely eliminate EDCs, Wojnarowicz et al. assessed the removal of EDCs by three methods of wastewater filtration using the C-fin assay (182). Despite clearing conventional contaminants, all three treatments produced WWEs that increased $\mathrm{TH}$-sensitive gene expression (thibz, thra, thrb) upon exposure (Table 4). The treatment types also had conflicting results in their ability to clear $\mathrm{TH}$ signaling effects depending upon the season in which the WWEs were collected (Table 4) (182). In a later study, Wojnarowicz et al. demonstrated the inefficiency of municipal wastewater treatment plants by showing that there is little difference in the endocrine-disrupting potential of WWE to that of the original influent using TH-mediated molecular endpoints and C-fin assays (Table 4) (183).

The considerable compositional variation within WWEs poses a challenge when assessing their endocrine disrupting potential. Heerema et al. generated a wastewater standard composed of common PPCPs to evaluate the exposure effects of the simulated WWE and test the efficiency of wastewater treatment systems (36). After filtration using an anaerobic membrane bioreactor (AnMBR), the standard WWE induced a significant upregulation of TH-sensitive thibz in the olfactory epithelium of $R$. catesbeiana

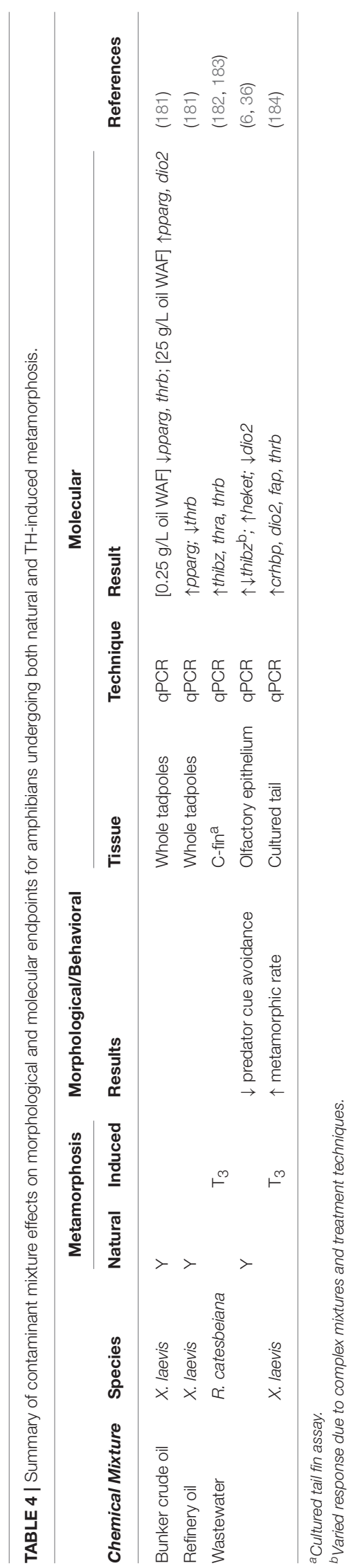


tadpoles. This suggests that the effluent was influencing THdependent pathways (Table 4). This study also assessed the behavioral effects, particularly predator cue avoidance, associated with WWE exposure. Once a tadpole is exposed to $\mathrm{T}_{3}$, it will stop responding to a simulated predator cue (36). WWE exposure mimicked the effects of $\mathrm{T}_{3}$ signaling in the olfactory epithelium and decreased predator cue avoidance (36). As a follow-up to this work, Jackman et al. showed that membrane enhanced biological phosphorous removal (MEBPR) performed better at removing EDCs from WWE than AnMBR (6). However, both effluent types resulted in the perturbation of TH-responsive gene transcript levels in the olfactory epithelium. TH agonist activity was observed in the AnMBR WWE and antagonist activity from MEBPR WWE, likely reflective of the influent source material (Table 4).

\section{Petroleum Oil Products}

Oil spills from a variety of sources can contaminate freshwater systems, thereby affecting the local biota (189). Major toxic components of oils, such as napthenic acid (NA) and polycyclic aromatic hydrocarbons (PAHs), are dispersed within watersoluble fractions after a spill $(190,191)$. NA and PAHs act as EDCs in amphibians. NA can directly reduce the rate of metamorphosis in $X$. tropicalis and $R$. pipiens and PAHs from tar-based pavement sealers can significantly reduce the rate of metamorphosis in X. laevis (Supplementary Table 1) (192, 193). The endocrine disrupting potential of these compounds seems to be quite persistent in the environment as $R$. sylvatica tadpoles exposed to pond water from wetlands proximal to reclaimed oil sands had significantly altered $\mathrm{T}_{3} / \mathrm{T}_{4}$ ratios and had accelerated or delayed rates of metamorphosis depending on the age of the reclaimed wetland (Supplementary Table 1) (194).

The effects of NA and PAHs on TH-sensitive gene expression was evaluated by exposing $X$. laevis tadpoles to simulated oil spill conditions using water accommodated fractions (WAF). WAFs were prepared using bunker crude oil or refinery oil (181). Bunker crude WAF exposures resulted in a significant decrease in dio2 and thrb and differential expression of pparg at various WAF concentrations (Table 4). Refinery WAF exposures resulted in a significant decrease in thrb expression and a significant increase in pparg expression (Table 4). Therefore, water soluble components of oil spills can adversely affect $\mathrm{TH}$-sensitive gene expression critical for amphibian metamorphosis.

\section{EFFECTS OF ENVIRONMENTAL FACTORS}

\section{Temperature}

Temperature serves as an important environmental cue for seasonality changes. As such, poikilothermic anurans have evolved to allow this environmental factor to serve as a critical cue in their developmental program. The role of temperature in modulating developmental timing is clearly demonstrated during natural metamorphosis when warmer temperatures lead to increased endogenous $\mathrm{T}_{3}$ and thereby a faster metamorphic rate (Supplementary Table 2) (195-198). Along with the increase in $\mathrm{TH}$ levels, there is an upregulation of $\mathrm{TH}$-regulated transcripts (including thra, thrb, thibz, dio2, and dio3) that initiate the metamorphic program (Table 5) (195, 202).

Conversely, metamorphic rate slows as temperatures decrease and can be halted altogether at $4-5^{\circ} \mathrm{C}$ (Supplementary Table 1) (203, 207, 208). Although premetamorphic tadpoles will not undergo precocious TH-induced metamorphosis at cold temperatures, a TH-induced memory is established whereby the metamorphic program resumes when permissive temperatures are attained, even when no TH signal remains (207). This cold temperature arrest is observed at the transcriptomic level (Table 5) $(65,203,204,209)$. Hammond et al. induced metamorphosis at $5^{\circ} \mathrm{C}$ in premetamorphic $R$. catesbeiana tadpoles through $\mathrm{T}_{3}$ exposures and assessed transcript responses in the brain, liver, back skin, tail fin, and lung (65). Across all tissues, thrb did not show the rapid induction observed at permissive temperatures. Transcripts encoding the transcription factor thibz, however, were upregulated in response to $T_{3}$ in all tissues, although this was not found in the liver by Suzuki et al. (Table 5) (203). Other $\mathrm{TH}$ response genes, including dio2, dio3, cebp1, klf9, and transcripts encoding urea cycle and energy metabolism enzymes showed varied responses across tissues, indicating there may be a tissue-specific response to $\mathrm{T}_{3}$ in cold temperatures $(65,202-204)$. Cold temperatures also inhibited the $\mathrm{T}_{3}$-induction of plasma glucose and decreased lipid polyunsaturation consistent with an effect on energy metabolism in tadpoles (Table 5) (203).

Regulation of chromatin structure is postulated to be a mechanism by which this differential gene expression occurs at permissive and non-permissive temperatures [reviewed by Hammond et al. (210)]. Using chromatin immunoprecipitation, Mochizuki et al. found that upon $\mathrm{T}_{3}$ exposure of $R$. catesbeiana at $4^{\circ} \mathrm{C}$ compared to $28^{\circ} \mathrm{C}$, there was decreased association of positive transcription histone $\mathrm{H} 3 \mathrm{~K} 36$ marks within two known temperature responding genes in the liver: thrb and cebp1 (Table 5) (204). How histone post-translational modifications may differentially regulate genes with upregulated transcription in cold temperatures and simultaneously establish a molecular memory of the TH signal to be activated under permissive conditions is unknown. As changing climate becomes an increasing threat to declining frog populations, it is critical to understand the effect that temperature has on the proper regulation of $\mathrm{TH}$ signaling during development.

\section{Ultraviolet B Radiation}

Ultraviolet B radiation (UVBR) is becoming a growing concern as stratospheric ozone levels deplete (211). Paired with an increasing penetration of UVBR into the water column (212), embryo and tadpole stages, which reside in aquatic environments, are at a greater risk. Metamorphic or developmental consequences of UVBR exposure on these more sensitive stages varies depending on species and life stage exposures [reviewed in Croteau (205)]. Blocked or delayed postembryonic development is the most commonly seen defect upon UVBR exposure (Supplementary Table 1) (213, 214). Croteau et al. examined the relationship between UVBR-induced developmental delays in $R$. pipiens and whether it may be related to the disruption of $\mathrm{TH}$ signaling (206). Exposure 


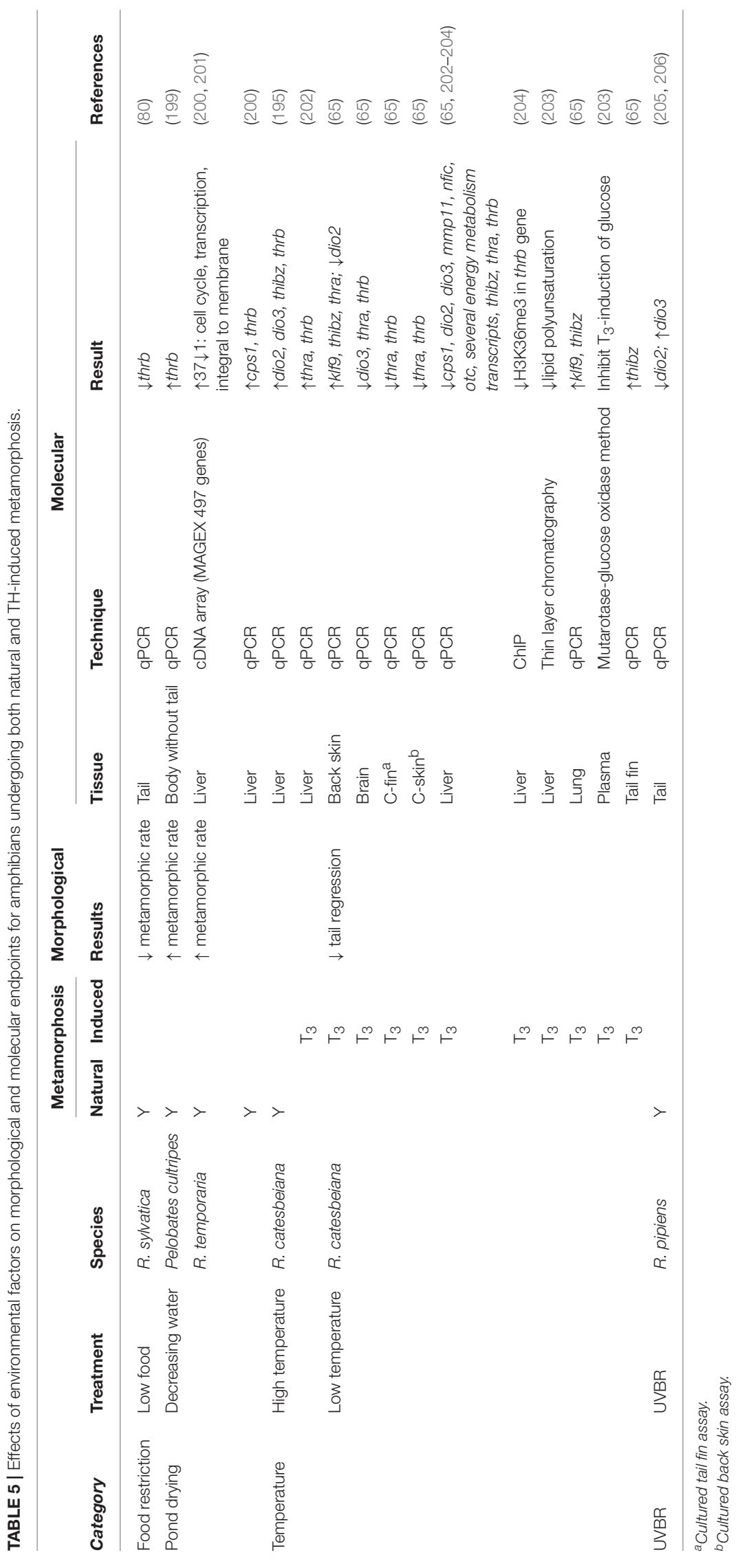


to UVBR showed no effect on total body $\mathrm{T}_{3}$ or brain CRF levels, indicating that synthesis of $\mathrm{TH}$ through the HPT axis is unlikely affected, although total $\mathrm{T}_{4}$ was not measured (206). Rather, UVBR effects may act locally on peripheral tissues. Increased dio 3 found in the tail during stages preceding the observed morphological delay may cause decreased local TH through enhanced turnover (Table 5). There is also decreased expression of dio2, which may act to further regulate the activity of THs through decreased conversion of $\mathrm{T}_{4}$ to $\mathrm{T}_{3}$ (2). This local response highlights the need to look at various tissues as their response to UVBR may differ leading to uncoordinated metamorphosis. As levels of UVBR are expected to rise, it is imperative to determine its mechanism of action in $\mathrm{TH}$ disruption, especially for sensitive life stages like postembryonic development.

\section{Photocycle: Light-Dark Cycle Implications}

Endocrine systems are entrained to the circadian clock. The $\mathrm{TH}$ axis is no exception, with THs following a rhythmic $24 \mathrm{~h}$ cycle (215). As photoperiod, along with temperature, is an environmental cue for seasonality changes, it is not surprising that many studies have found that the light:dark (L:D) cycle has an impact on metamorphic rate (Supplementary Table 1) (216218). In the majority of studies, increasing photophase (light phase) of a $24 \mathrm{~h} \mathrm{~L}: \mathrm{D}$ cycle or decreasing cycle length increases metamorphic response to TH stimulation (218). However, when the $24 \mathrm{~h}$ cycle is not maintained, the L:D ratio is no longer indicative of metamorphic rate. In a case where Wright et al. found decreased tail reduction with an increased photophase, there was 18L:12D, which surpasses the standard $24 \mathrm{~h}$ cycle (219).

The mechanism by which the L:D cycle alters THinduced metamorphosis is poorly understood. It has been determined that altering the L:D cycle leads to differences in the fluctuating rhythm of $\mathrm{T}_{4}$ [reviewed by Wright (215)] (Supplementary Table 2). However, under any L:D cycle, there is an inextricable rise in T4 as development progresses until metamorphic climax (220). This indicates that the alteration in metamorphic rate is not due to a disruption in $\mathrm{TH}$ concentration. It is more likely that a disruption in the circadian rhythms of THs may lead to different interactions with agonists and antagonists $(220,221)$. It remains to be determined how this variation in cycling affects $\mathrm{TH}$ responses at the transcriptomic level, which may provide a better mechanistic understanding of how the L:D cycle impacts metamorphic timing.

\section{Pond Drying}

Many tadpole species reside in ephemeral bodies of water. Loss of these temporary habitats is fatal to water-dwelling tadpoles; therefore, it is unsurprising that across species, there is a positive correlation between pond desiccation rate and speed of development into terrestrial frogs (Supplementary Table 1) $(198,222,223)$. The ability to translate this environmental cue to a phenotypic response is proposed to occur through the HPT axis. CRF levels increase in response to habitat desiccation, preceding the morphological observation of hastened metamorphic rate (224). This stress-induced increase in CRF leads to augmented secretion of THs (Supplementary Table 2) (199, 224, 225), which can be reversed through exposure to CRF antagonists (225). This increase in activity in the HPT axis leads to accelerated metamorphosis through the downstream regulation of $\mathrm{TH}$ response genes. Johansson et al. used cDNA microarray and qPCR analyses to determine the hepatic transcriptomic response to simulated pond drying in R. temporaria (Table 5) (200). This study found that classic $\mathrm{TH}$ response genes, such as thra and thrb, increase along with decreasing water levels, which corroborates previous findings that decreased water levels lead to increased TH levels and higher expression of thrb in the blood (199). More liver-specific $\mathrm{TH}$ response transcripts also demonstrated significant changes, including urea cycle enzyme cps1 (200). The ability of tadpoles to respond to decreasing water levels demonstrates the plasticity of TH-mediated metamorphosis that allows tadpoles to adapt to changing environments.

\section{Food Restriction}

Similar to pond drying, availability of other resources, such as food, plays an important role in developmental timing. As metamorphosis often entails a niche transition from aquatic to terrestrial environments, it stands to reason that when resources available in the aquatic habitat are no longer sufficient, it may prompt a transition to a new environment where resources may be greater or competition lower. The impact of food restriction on metamorphosis has varied results (Supplementary Table 1) (226-231). Complete starvation and consistently low or actively decreasing food levels leads to increased metamorphic rate in Scaphiopus (S.) hammondii (226), Phrynobatrachus guineensis (227), and R. temporaria (228). In contrast, consistently low or actively decreasing food sources reduces metamorphic rate in Hyla cineria and Hyla gratiosa $(229,230)$. The varied response may be due to the different life histories of the different species. Another contributing factor is the developmental timing of food restriction. D'Angelo et al. determined that there is a critical developmental point, around limb bud formation, before which metamorphosis will be stalled but after which, metamorphosis will be accelerated (232). Bulaeva et al. restricted food for $R$. sylvatica prior to this critical time point and found that the decrease in metamorphic rate coincided with a decrease in thrb transcript levels, indicating disrupted $\mathrm{TH}$ signaling (Table 5) (50). In contrast, histological analysis of the thyroid gland of the tadpoles starved past this critical period give evidence to a short burst of increased secretory activity (232). Evidence of this burst of thyroid activity was corroborated in vitro by Wright et al. who found a brief increase in secretion of $\mathrm{T}_{4}$ in cultured thyroids excised from $R$. catesbeiana tadpoles that were starved for 1 week compared to those that were fed consistently (Supplementary Table 2) (233). Boorse and Denver also found increased levels of $\mathrm{T}_{3}$ and $\mathrm{T}_{4}$ in vivo after food restriction in $S$. hammondii (234). Future studies have yet to determine how this burst of $\mathrm{T}_{4}$ affects the $\mathrm{TH}$-induced transcriptomic program leading to increased metamorphic rate. 


\section{Combined Chemical and Environmental Effects}

It is well-established that individual environmental factors play an important role in the proper regulation of $\mathrm{TH}$ signaling during metamorphosis. In natural systems, however, temperature, photoperiod, UVBR intensity, and resource restriction (ponddrying and food restriction) effects are inextricably linked. Not only are they influenced by each other, but frogs are simultaneously exposed to all anthropogenic chemicals that enter their habitat. The combinatorial effect of environmental and chemical stressors can be exponentially more detrimental as they may work synergistically to increase toxicity or reduce an organism's capacity to respond to other stressors.

The additive toxicity of UVBR and various chemical contaminants has been well-documented [reviewed by Blaustein et al. (235) and Croteau et al. (205)]; however, the sublethal effects on development have not been as well-studied. Crump et al. found that environmentally-relevant levels of the estrogenic compound, octylphenol, had a combined effect with UVBR that increased metamorphic rate, unlike exposure to either factor individually (236). The TH-based mechanism by which this combined effect occurs was further studied by Croteau et al. who observed that at earlier developmental stages, there is a significant increase in thrb upon exposure to UVBR combined with octylphenol compared to either factor alone (Table 6) (206). This indicated that TH-signaling during metamorphosis is being differentially affected by the combination of chemical and environmental factors.

Increases in metamorphic rate induced by warmer temperatures are compounded by concomitant contaminant exposures that also induce metamorphosis. Freitas et al. exposed $R$. catesbeiana tadpoles to the pesticide diuron and its metabolite, 3,4-dichloroaniline, at 28 and $34^{\circ} \mathrm{C}$ and observed an increased developmental response to both chemicals at the higher temperature compared to either exposure at the lower temperature or the temperature-matched control (Table 6) (195). This combination of exposures increased the expression of dio 2 and the warm temperature plus diuron exposure increased klf9, which likely explains the observed change in metamorphic rate.

Contaminants can also have an impact on the ability of environmental cues to regulate developmental timing. For species that overwinter as tadpoles, transitioning while the temperatures are still too low could be fatal. Hammond et al. investigated the impact of two known TH EDCs discussed above, ibuprofen, and TCS, on the temperature-controlled TH response in premetamorphic $R$. catesbeiana tadpoles (Table 6) $(28,29,65)$. After a $48 \mathrm{~h}$ exposure to each contaminant at $5^{\circ} \mathrm{C}$, both produced a significant increase in $k l f 9$ in a cultured $R$. catesbeiana back skin biopsy assay (C-skin). In contrast, when tail fin biopsies from the same tadpoles were cultured in a C-fin assay, exposed to the chemicals at $5^{\circ} \mathrm{C}$ and then shifted into clean media at more permissive temperatures, there was a significant decrease in thrb after TCS exposure (Table 6). This indicates that both EDCs have the potential to disrupt proper $\mathrm{TH}$ signaling during the cold-induced establishment of TH molecular memory. As well, TCS exposure at cold temperatures may be remembered when warmer temperatures occur, potentially leading to detrimental effects throughout metamorphosis.

Natural systems contain combinations of environmental factors and chemical contaminants. It is therefore important to conduct studies with multiple stressors to provide more meaningful information. A changing climate and intensifying UVBR combined with increased anthropogenic contamination are escalating the need to elucidate how these factors influence critical biological systems such as TH signaling in metamorphosis, both independently and in combination with each other.

\section{CONCLUDING CONSIDERATIONS}

As our understanding of the disruption of TH-dependent metamorphosis by environmental and chemical perturbations improves, it is apparent that there are several pressing challenges that must be addressed. Anurans are keystone sentinel species that can portend the deleterious and combinatorial effects of contaminants and changing climate effects on all trophic levels within different environmental niches. While it is important to understand the mechanisms affected by a single contaminant, the environmental context in which the exposure occurs must be considered. Within an affected environment, disruption of TH-dependent metamorphosis is rarely, if ever, derived from an isolated contaminant. To this end, the interplay between environmental conditions and complex mixtures should be assessed in tandem to ascertain the cumulative effects on THdependent metamorphosis.

Amphibian screening assays have been developed that address the need for the timely detection of contaminants that affect

TABLE 6 | Combined effects of chemical contaminants and environmental factors on morphological and molecular endpoints for amphibians undergoing both natural and TH-induced metamorphosis.

\begin{tabular}{|c|c|c|c|c|c|c|c|c|c|c|}
\hline \multirow[b]{2}{*}{ Category } & \multicolumn{2}{|c|}{ Treatment } & \multirow[b]{2}{*}{ Species } & \multicolumn{2}{|c|}{ Metamorphosis } & \multirow{2}{*}{$\begin{array}{l}\text { Morphological } \\
\text { Results }\end{array}$} & \multicolumn{3}{|c|}{ Molecular } & \multirow[b]{2}{*}{ References } \\
\hline & Environmental & Chemical & & Natural & Induced & & Tissue & Technique & Result & \\
\hline \multirow[t]{5}{*}{ Temperature } & $28^{\circ} \mathrm{C}$ & Diuron & R. catesbeiana & Y & & & Liver & qPCR & $\uparrow$ thibz & $(195)$ \\
\hline & $34^{\circ} \mathrm{C}$ & & R. catesbeiana & Y & & & Liver & qPCR & $\uparrow$ dio2, klf9 & (195) \\
\hline & $5^{\circ} \mathrm{C}$ & Ibuprofen & R. catesbeiana & & $\mathrm{T}_{3}$ & & C-skin & qPCR & $\uparrow k l f 9$ & (65) \\
\hline & $5^{\circ} \mathrm{C}$ & Triclosan & R. catesbeiana & & $\mathrm{T}_{3}$ & & C-skin & qPCR & $\uparrow k l f 9$ & (65) \\
\hline & $5^{\circ} \mathrm{C}$ to $24^{\circ} \mathrm{C}$ & & R. catesbeiana & & $\mathrm{T}_{3}$ & & C-fin & qPCR & $\uparrow t h r b$ & (65) \\
\hline UVBR & UVBR & 4-Tert-octylphenol & R. pipiens & Y & & $\downarrow$ metamorphic rate & Tail & qPCR & $\uparrow$ thrb & (236) \\
\hline
\end{tabular}


TH-dependent metamorphosis and that accurately reflect in vivo changes (237). The Xenopus metamorphosis assay (XEMA) was initially conceived to assay the TH-disrupting capacity of compounds and derivatives of XEMA have since been developed $(40,78,238)$. Similarly, cell lines and serum-free organ culture techniques, including tail fin (C-fin) and back skin (C-skin), have utility in ascertaining TH disrupting effects (81, 209, 239, 240). Organ culture techniques are particularly useful since they retain the three-dimensional structure of tissues while facilitating a repeated-measures analysis, including the rapid assessment of TH-dependent molecular changes in gene expression. As such, organ cultures provide an informative and complementary counterpart to conventional morphological and histological assessments (89). As changes in gene expression typically precede morphological variations during metamorphosis, transcriptomic assessments provide a more timely and sensitive assessment of altered metamorphic trajectories that may not be readily observed as a pathological phenotype. Non-lethal molecular assessments of tail fin biopsies are additionally well-suited to long-term studies involving repeated measures (84).

Careful consideration should be paid to the selection of amphibian species used to assess the ramifications of environmental contaminants on metamorphic dysfunction. Although Xenopus species are widely accepted animal models in research laboratories, their natural habitats, life cycles and physiologies are quite distinct from other anurans, such as Ranids, Hylids, and Bufonids (241). Consequently, physiological responses to environmental or chemical perturbations can differ widely between anurans. Therefore, the adoption of amphibian models that closely resemble native species in affected areas would provide the most meaningful assessments of $\mathrm{TH}$ dependent metamorphic disruptions (242).

The use of qPCR, DNA microarrays, and RNA-seq in conjunction with morphological characterizations have demonstrated the sensitive and differential tissue-specific gene expression arising from environmental or toxicant exposures during TH-dependent metamorphosis (23, 32, 34, 209, 243). As cutting-edge 'omics techniques-transcriptomics, genomics, epigenomics, proteomics, and metabolomics-are increasingly utilized with bioinformatics in ecotoxicology studies, it will be possible to elucidate the mechanisms affected by TH-disrupted metamorphosis in a comprehensive manner (210, 244-247). Considerable progress has been made in recent years with the sequencing of the $X$. laevis, $X$. tropicalis, Nanorana parkeri, and $R$. catesbeiana genomes and increasing numbers of transcriptomes; all of which are invaluable resources (247-251). Thoughtful consideration of the species, tissue-specificity, and developmental stage observed; the timing and duration of exposure and study conditions will be indispensable in establishing large-scale studies for meaningful meta-analyses.

Additional attention should be paid to the examination of metabolized derivatives that may be more potent than the parent congener. Biotransformed derivatives can be generated through metabolic activities within the affected organism or by physical transformation in the environment (for instance, weathering or photo-oxidation) (252-254). Compared to the parent congener, activated derivatives may consequently be more stable, better able to mimic or target different aspects of $\mathrm{TH}$ regulation (i.e., TH receptors, metabolizing enzymes, etc.) or be rendered more lipophilic, which would facilitate their uptake or excretion. The mechanisms underlying increased derivative toxicity, whether they are independent of or compromise $\mathrm{TH}$ regulation, is an important area of study.

With more than $70 \%$ of $\sim 7,000$ extant amphibian species threatened and declining around the world, there is an urgent need to address how anthropogenically-derived environmental disruptions are affecting vulnerable species (255). Humans are not impervious to the deleterious changes affecting wildlife; metabolomic studies demonstrated that metabolites altered during anuran metamorphosis are also associated with human disease outcomes (245). Moreover, a recent study demonstrated that TH-related gene expression and early brain development were altered in $X$. laevis following exposure to concentrations of chemicals (including TCS, phthalates, pesticides, and others) detected in human amniotic fluid (256). Given the developmental parallels between TH-dependent amphibian metamorphosis and mammalian postembryonic development, it is apparent that exposures negatively affecting amphibians will also impair human health (257). As sobering as these ramifications are, such deleterious outcomes are not necessarily irrevocable if timely remediation actions are taken. The genomic plasticity afforded by epigenetic alterations, while able to endure maladaptive stresses, similarly has the posited capacity to adapt to remediation. Such potentially ameliorative effects merit further investigation that would be best addressed using the genomics-based approaches discussed in conjunction with morphological analyses. Remediation efforts will require understanding the complexity of the ecological stresses and the interplay between complex toxicant mixtures and changing environmental conditions. The unique sensitivity of anurans to $\mathrm{TH}$ ideally positions them as indicators for not only metamorphic and developmental effects, but also for the fitness and reproductive success of all vertebrates that depend upon $\mathrm{TH}$ function.

\section{AUTHOR CONTRIBUTIONS}

All authors contributed to the conceptualization, literature research and interpretation, writing, and editing of the manuscript.

\section{ACKNOWLEDGMENTS}

The authors gratefully acknowledge the continued support of the Natural Sciences and Engineering Research Council of Canada (NSERC) that has funded much of the cited work from the $\mathrm{CH}$ laboratory. EK is a recipient of a NSERC CGS-M scholarship.

\section{SUPPLEMENTARY MATERIAL}

The Supplementary Material for this article can be found online at: https://www.frontiersin.org/articles/10.3389/fendo. 2019.00276/full\#supplementary-material 


\section{REFERENCES}

1. Tata JR. Amphibian metamorphosis as a model for the developmental actions of thyroid hormone. Mol Cell Endocrinol. (2006) 246:1020. doi: 10.1016/j.mce.2005.11.024

2. Shi Y-B. Amphibian Metamorphosis: From Morphology to Molecular Biology. New York, NY: Wiley-Liss (1999).

3. Just, JJ, Kraus-Just J, Check DA. Survey of chordate metamorphosis. In: Gilbert LI, Frieden E, editors. Metamorphosis. Boston, MA: Springer (1981). p. 265-326.

4. Dodd MHI, Dodd JM. The biology of metamorphosis. In: Lofts B, editor. Physiology of the Amphibia, New York, NY: Academic Press, 467-599.

5. Brown DD, Cai L. Amphibian metamorphosis. Dev Biol. (2007) 306:2033. doi: 10.1016/j.ydbio.2007.03.021

6. Jackman KW, Veldhoen N, Miliano RC, Robert BJ, Li L, Khojasteh A, et al. Transcriptomics investigation of thyroid hormone disruption in the olfactory system of the Rana [Lithobates] catesbeiana tadpole. Aquat Toxicol Amst Neth. (2018) 202:46-56. doi: 10.1016/j.aquatox.2018.06.015

7. Maher SK, Wojnarowicz P, Ichu T-A, Veldhoen N, Lu L, Lesperance M, et al. Rethinking the biological relationships of the thyroid hormones, lL-thyroxine and 3,5,3'-triiodothyronine. Comp Biochem Physiol Part D Genomics Proteomics. (2016) 18:44-53. doi: 10.1016/j.cbd.2016.04.002

8. Schroeder A, Jimenez R, Young B, Privalsky ML. The Ability of thyroid hormone receptors to sense $\mathrm{T}_{4}$ as an agonist depends on receptor isoform and on cellular cofactors. Mol Endocrinol. (2014) 28:745757. doi: 10.1210/me.2013-1335

9. Schroeder AC, Privalsky ML. Thyroid hormones, $\mathrm{T}_{3}$ and $\mathrm{T}_{4}$, in the brain. Front Endocrinol. (2014) 5:40. doi: 10.3389/fendo.2014.00040

10. Helbing CC, Werry K, Crump D, Domanski D, Veldhoen N, Bailey CM. expression profiles of novel thyroid hormone-responsive genes and proteins in the tail of Xenopus laevis tadpoles undergoing precocious metamorphosis. Mol Endocrinol. (2003) 17:1395-409. doi: 10.1210/me.2002-0274

11. Helbing CC, Maher SK, Han J, Gunderson MP, Borchers C. Peering into molecular mechanisms of action with frogSCOPE. Gen Comp Endocrinol. (2010) 168:190-198. doi: 10.1016/j.ygcen.2010.01.012

12. Sachs LM, Buchholz DR. Frogs model man: In vivo thyroid hormone signaling during development. Genesis. (2017) 55:e23000. doi: 10.1002/dvg.23000

13. Buchholz DR. More similar than you think: frog metamorphosis as a model of human perinatal endocrinology. Dev Biol. (2015) 408:18895. doi: 10.1016/j.ydbio.2015.02.018

14. Buchholz DR. Xenopus metamorphosis as a model to study thyroid hormone receptor function during vertebrate developmental transitions. Mol Cell Endocrinol. (2017) 459:64-70. doi: 10.1016/j.mce.2017.03.020

15. Buchholz DR, Shi Y-B. Dual function model revised by thyroid hormone receptor alpha knockout frogs. Gen Comp Endocrinol. (2018) 265:2148. doi: 10.1016/j.ygcen.2018.04.020

16. Kulkarni SS, Buchholz DR. Corticosteroid signaling in frog metamorphosis. Gen Comp Endocrinol. (2014) 203:225-31. doi: 10.1016/j.ygcen.2014.03.036

17. Colborn T. Clues from wildlife to create an assay for thyroid system disruption. Environ Health Perspect. (2002) 110(Suppl. 3):363-7. doi: 10.1289/ehp.02110s3363

18. Scholz S, Renner P, Belanger SE, Busquet F, Davi R, Demeneix BA. Alternatives to in vivo tests to detect endocrine disrupting chemicals (EDCs) in fish and amphibians - screening for estrogen, androgen and thyroid hormone disruption. Crit Rev Toxicol. (2013) 43:4572. doi: 10.3109/10408444.2012.737762

19. Hayes TB, Case P, Chui S, Chung D, Haeffele C, Haston K, Pesticide mixtures, endocrine disruption, and amphibian declines: are we underestimating the impact? Environ Health Perspect. (2006) 114(Suppl. 1):40-50. doi: 10.1289/ehp.8051

20. Opitz R, Kloas W. Developmental regulation of gene expression in the thyroid gland of Xenopus laevis tadpoles. Gen Comp Endocrinol. (2010) 168:199-208. doi: 10.1016/j.ygcen.2010.04.013

21. Opitz R, Hartmann S, Blank T, Braunbeck T, Lutz I, Kloas W. Evaluation of histological and molecular endpoints for enhanced detection of thyroid system disruption in Xenopus laevis tadpoles. Toxicol Sci. (2006) 90:33748. doi: 10.1093/toxsci/kfj083
22. Veldhoen N, Crump D, Werry K, Helbing CC. Distinctive gene profiles occur at key points during natural metamorphosis in the Xenopus laevis tadpole tail. Dev Dyn. (2002) 225:457-68. doi: 10.1002/dvdy.10175

23. Veldhoen N, Propper CR, Helbing CC. Enabling comparative gene expression studies of thyroid hormone action through the development of a flexible real-time quantitative PCR assay for use across multiple anuran indicator and sentinel species. Aquat Toxicol. (2014) 148:16273. doi: 10.1016/j.aquatox.2014.01.008

24. Kolpin DW, Furlong ET, Meyer MT, Thurman EM, Zaugg SD, Barber LB, et al. Pharmaceuticals, hormones, and other organic wastewater contaminants in U.S. streams, 1999-2000: a national reconnaissance. Environ Sci Technol. (2002) 36:1202-11. doi: 10.1021/es011055j

25. Fekadu S, Alemayehu E, Dewil R, Van der Bruggen B. Pharmaceuticals in freshwater aquatic environments: a comparison of the African and European challenge. Sci Total Environ. (2018) 654:324-37. doi: 10.1016/j.scitotenv.2018.11.072

26. Hinther A, Bromba CM, Wulff JE, Helbing CC. Effects of triclocarban, triclosan, and methyl triclosan on thyroid hormone action and stress in frog and mammalian culture systems. Environ Sci Technol. (2011) 45:5395402. doi: 10.1021/es1041942

27. Marlatt VL, Veldhoen N, Lo BP, Bakker D, Rehaume V, Vallée K, et al. Triclosan exposure alters postembryonic development in a Pacific tree frog (Pseudacris regilla) Amphibian Metamorphosis Assay (TREEMA). Aquat Toxicol. (2013) 126:85-94. doi: 10.1016/j.aquatox.2012.10.010

28. Veldhoen N, Skirrow RC, Osachoff H, Wigmore H, Clapson DJ, Gunderson MP, et al. The bactericidal agent triclosan modulates thyroid hormone-associated gene expression and disrupts postembryonic anuran development. Aquat Toxicol. (2006) 80:217-27. doi: 10.1016/j.aquatox.2006.08.010

29. Veldhoen N, Skirrow RC, Brown LLY, van Aggelen G, Helbing CC. Effects of acute exposure to the non-steroidal anti-inflammatory drug ibuprofen on the developing North American bullfrog (Rana catesbeiana) tadpole. Environ Sci Technol. (2014) 48:10439-47. doi: 10.1021/es502539g

30. Degitz SJ, Holcombe GW, Flynn KM, Kosian PA, Korte JJ, Tietge JE. Progress towards development of an amphibian-based thyroid screening assay using Xenopus laevis. Organismal and thyroidal responses to the model compounds 6-propylthiouracil, methimazole, and thyroxine. Toxicol Sci. (2005) 87:353-364. doi: 10.1093/toxsci/kfi246

31. Zhang F, Degitz SJ, Holcombe GW, Kosian PA, Tietge J, Veldhoen N, et al. Evaluation of gene expression endpoints in the context of a Xenopus laevis metamorphosis-based bioassay to detect thyroid hormone disruptors. Aquat Toxicol. (2006) 76:24-36. doi: 10.1016/j.aquatox.2005.09.003

32. Helbing CC, Bailey CM, Ji L, Gunderson MP, Zhang F, Veldhoen N, et al. Identification of gene expression indicators for thyroid axis disruption in a Xenopus laevis metamorphosis screening assay Part 1. Effects on the brain. Aquat Toxicol. (2007) 82:227-41. doi: 10.1016/j.aquatox.2007.02.013

33. Coady K, Marino T, Thomas J, Currie R, Hancock G, Crofoot J, et al. Evaluation of the amphibian metamorphosis assay: exposure to the goitrogen methimazole and the endogenous thyroid hormone L-thyroxine. Environ Toxicol Chem. (2010) 29:869-80. doi: 10.1002/etc.74

34. Helbing CC, Ji L, Bailey CM, Veldhoen N, Zhang F, Holcombe GW, et al. Identification of gene expression indicators for thyroid axis disruption in a Xenopus laevis metamorphosis screening assay Part 2. Effects on the tail and hindlimb. Aquat Toxicol. (2007) 82:215-26. doi: 10.1016/j.aquatox.2007.02.014

35. Opitz R, Schmidt F, Braunbeck T, Wuertz S, Kloas W. Perchlorate and ethylenethiourea induce different histological and molecular alterations in a non-mammalian vertebrate model of thyroid goitrogenesis. Mol Cell Endocrinol. (2009) 298:101-14. doi: 10.1016/j.mce.2008. 08.020

36. Heerema JL, Jackman KW, Miliano RC, Li L, Zaborniak TSM, Veldhoen $\mathrm{N}$, et al. Behavioral and molecular analyses of olfaction-mediated avoidance responses of Rana (Lithobates) catesbeiana tadpoles: Sensitivity to thyroid hormones, estrogen, and treated municipal wastewater effluent. Horm Behav. (2018) 101:85-93. doi: 10.1016/j.yhbeh.2017.09.016

37. Rotermann M, Sanmartin C, Hennessy D, Arthur M. Prescription medication use by Canadians aged 6 to 79. Health Rep. (2014) 25:9. 
38. Brown AK, Wong CS. Distribution and fate of pharmaceuticals and their metabolite conjugates in a municipal wastewater treatment plant. Water Res. (2018) 144:774-83. doi: 10.1016/j.watres.2018.08.034

39. Doerge DR, Takazawa RS. Mechanism of thyroid peroxidase inhibition by ethylenethiourea. Chem Res Toxicol. (1990) 3:98-101.

40. Opitz R, Braunbeck T, Bögi C, Pickford DB, Nentwig G, Oehlmann J, et al. Description and initial evaluation of a Xenopus metamorphosis assay for detection of thyroid system-disrupting activities of environmental compounds. Environ Toxicol Chem. (2005) 24:653. doi: 10.1897/04-214R.1

41. Carlsson G, Norrgren L. The impact of the goitrogen 6propylthiouracil (PTU) on West-African clawed frog (Xenopus tropicalis) exposed during metamorphosis. Aquat Toxicol. (2007) 82:55-62. doi: 10.1016/j.aquatox.2007.01.005

42. Oka T, Miyahara M, Yamamoto J, Mitsui N, Fujii T, Tooi O, et al. Application of metamorphosis assay to a native Japanese amphibian species, Rana rugosa, for assessing effects of thyroid system affecting chemicals. Ecotoxicol Environ Saf. (2009) 72:1400-5. doi: 10.1016/j.ecoenv.2009.03.012

43. Nieuwkoop PD, Faber J (eds.). Normal table of Xenopus laevis (Daudin). A Systematical and Chronological Survey of the Development From the Fertilized Egg Till the End of Metamorphosis. New York, NY and London: Garland Publishing, Inc. (1994).

44. Propylthiouracil, and Methimazole, and Carbimazole-Related Hepatotoxicity: Expert Opinion on Drug Safety: Vol 13, No 10. Available online at: https:// www.tandfonline.com/doi/full/10.1517/14740338.2014.953796 (accessed December 5, 2018).

45. Hayes TB. Steroids as potential modulators of thyroid hormone activity in anuran metamorphosis. Am Zool. (1997) 37:18594. doi: 10.1093/icb/37.2.185

46. Frieden E, Naile B. Biochemistry of Amphibian Metamorphosis: 1. Enhancement of induced metamorphosis by glucocorticoids. Science. (1955) 121:37-9.

47. Vandorpe G, Kühn ER. Estradiol-17 $\beta$ silastic implants in female Rana ridibunda depress thyroid hormone concentrations in plasma and the in vitro 5'-monodeiodination activity of kidney homogenates. Gen Comp Endocrinol. (1989) 76:341-5. doi: 10.1016/0016-6480(89)90127-5

48. Brande-Lavridsen N, Christensen-Dalsgaard J, Korsgaard B. Effects of ethinylestradiol and the fungicide prochloraz on metamorphosis and thyroid gland morphology in Rana temporaria. Open Zool J. (2010) 3:716. doi: 10.2174/1874336601003020007

49. Yamauchi K, Prapunpoj P, Richardson SJ. Effect of diethylstilbestrol on thyroid hormone binding to amphibian transthyretins. Gen Comp Endocrinol. (2000) 119:329-39. doi: 10.1006/gcen.2000.7528

50. Bulaeva E, Lanctôt C, Reynolds L, Trudeau VL, Navarro-Martín L. Sodium perchlorate disrupts development and affects metamorphosis- and growthrelated gene expression in tadpoles of the wood frog (Lithobates sylvaticus). Gen Comp Endocrinol. (2015) 222:33-43. doi: 10.1016/j.ygcen.2015.01.012

51. Sim W-J, Lee J-W, Shin S-K, Song K-B, Oh J-E. Assessment of fates of estrogens in wastewater and sludge from various types of wastewater treatment plants. Chemosphere. (2011) 82:1448-53. doi: 10.1016/j.chemosphere.2010.11.045

52. Hunger R, Mantke A, Herrmann C, Mantke R. [Triclosan-coated sutures in colorectal surgery: assessment and meta-analysis of the recommendations of the WHO guideline]. Chir Z Alle Geb Oper Medizen. (2018) 90:3746 doi: 10.1007/s00104-018-0732-0

53. Weatherly LM, Gosse JA. Triclosan exposure, transformation, and human health effects. J Toxicol Environ Health B Crit Rev. (2017) 20:44769. doi: 10.1080/10937404.2017.1399306

54. Ribado JV, Ley C, Haggerty TD, Tkachenko E, Bhatt AS, Parsonnet J. Household triclosan and triclocarban effects on the infant and maternal microbiome. EMBO Mol Med. (2017) 9:1732-41. doi: 10.15252/emmm.201707882

55. Voelker R. Say goodbye to some antibacterials. JAMA. (2016) 316:1538. doi: 10.1001/jama.2016.14612

56. Fort DJ, Mathis MB, Hanson W, Fort CE, Navarro LT, Peter R, et al. Triclosan and thyroid-mediated metamorphosis in Anurans: differentiating growth effects from thyroid-driven metamorphosis in Xenopus laevis. Toxicol Sci. (2011) 121:292-302. doi: 10.1093/toxsci/kfr069
57. Fort DJ, Rogers RL, Gorsuch JW, Navarro LT, Peter R, Plautz JR. Triclosan and Anuran metamorphosis: no effect on thyroidmediated metamorphosis in Xenopus laevis. Toxicol Sci. (2010) 113:392-400. doi: 10.1093/toxsci/kfp280

58. Regnault C, Usal M, Veyrenc S, Couturier K, Batandier C, Bulteau A-L, et al. Unexpected metabolic disorders induced by endocrine disruptors in Xenopus tropicalis provide new lead for understanding amphibian decline. Proc Natl Acad Sci USA. (2018) 115:E4416-25. doi: 10.1073/pnas.1721267115

59. Helbing CC, van Aggelen G, Veldhoen N. Triclosan affects thyroid hormonedependent metamorphosis in Anurans. Toxicol Sci. (2011) 119:4178. doi: 10.1093/toxsci/kfq343

60. Helbing CC, Propper CR, Veldhoen N. Triclosan affects the thyroid axis of Amphibians. Toxicol Sci. (2011) 123:601-2. doi: 10.1093/toxsci/kfr127

61. Lindström A, Buerge IJ, Poiger T, Bergqvist P-A, Müller MD, Buser H-R. Occurrence and environmental behavior of the bactericide triclosan and its methyl derivative in surface waters and in wastewater. Environ Sci Technol. (2002) 36:2322-9. doi: 10.1021/es0114254

62. Sui Q, Cao X, Lu S, Zhao W, Qiu Z, Yu G. Occurrence, sources and fate of pharmaceuticals and personal care products in the groundwater: a review. Emerg Contam. (2015) 1:14-24. doi: 10.1016/j.emcon.2015.07.001

63. Ebele AJ, Abou-Elwafa Abdallah M, Harrad S. Pharmaceuticals and personal care products (PPCPs) in the freshwater aquatic environment. Emerg Contam. (2017) 3:1-16. doi: 10.1016/j.emcon.2016.12.004

64. Rainsford KD. Ibuprofen: pharmacology, efficacy and safety. Inflammopharmacology. (2009) 17:275-342. doi: 10.1007/s10787-009-0016-X

65. Hammond SA, Veldhoen N, Helbing CC. Influence of temperature on thyroid hormone signaling and endocrine disruptor action in Rana (Lithobates) catesbeiana tadpoles. Gen Comp Endocrinol. (2015) 219:615. doi: 10.1016/j.ygcen.2014.12.001

66. Davies H, Delistraty D. Evaluation of PCB sources and releases for identifying priorities to reduce PCBs in Washington State (USA). Environ Sci Pollut Res. (2016) 23:2033-41. doi: 10.1007/s11356-015-4828-5

67. Brouwer A, Morse DC, Lans MC, Gerlienke Schuur A, Murk AJ, KlassonWehler E, et al. Interactions of Persistent environmental organohalogens with the thyroid hormone system: mechanisms and possible consequences for animal and human health. Toxicol Ind Health. (1998) 14:5984. doi: 10.1177/074823379801400107

68. Gutleb AC, Appelman J, Bronkhorst M, van den Berg JHJ, Murk AJ. Effects of oral exposure to polychlorinated biphenyls (PCBs) on the development and metamorphosis of two amphibian species (Xenopus laevis and Rana temporaria). Sci Total Environ. (2000) 262:147-57. doi: 10.1016/S0048-9697(00)00598-2

69. Gutleb AC, Mossink L, Schriks M, van den Berg HJH, Murk AJ. Delayed effects of environmentally relevant concentrations of $3,3^{\prime}, 4,4^{\prime}$-tetrachlorobiphenyl (PCB-77) and non-polar sediment extracts detected in the prolonged-FETAX. Sci Total Environ. (2007) 381:307-15. doi: 10.1016/j.scitotenv.2007.03.002

70. Gutleb AC, Schriks M, Mossink L, Berg JHJ van den, Murk AJ. A synchronized amphibian metamorphosis assay as an improved tool to detect thyroid hormone disturbance by endocrine disruptors and apolar sediment extracts. Chemosphere. (2007) 70:93-100. doi: 10.1016/j.chemosphere.2007.06.048

71. Lehigh Shirey EA, Jelaso Langerveld A, Mihalko D, Ide CF. Polychlorinated biphenyl exposure delays metamorphosis and alters thyroid hormone system gene expression in developing Xenopus laevis. Environ Res. (2006) 102:20514. doi: 10.1016/j.envres.2006.04.001

72. Balch GC, Vélez-Espino LA, Sweet C, Alaee M, Metcalfe CD. Inhibition of metamorphosis in tadpoles of Xenopus laevis exposed to polybrominated diphenyl ethers (PBDEs). Chemosphere. (2006) 64:328-38. doi: 10.1016/j.chemosphere.2005.12.019

73. Yost AT, Thornton LM, Venables BJ, Sellin Jeffries MK. Dietary exposure to polybrominated diphenyl ether 47 (BDE-47) inhibits development and alters thyroid hormone-related gene expression in the brain of Xenopus laevis tadpoles. Environ Toxicol Pharmacol. (2016) 48:23744. doi: 10.1016/j.etap.2016.11.002

74. Zhang Y, Li Y, Qin Z, Wang H, Li J. A screening assay for thyroid hormone signaling disruption based on thyroid hormone-response gene expression 
analysis in the frog Pelophylax nigromaculatus. J Environ Sci. (2015) 34:14354. doi: 10.1016/j.jes.2015.01.028

75. Veldhoen N, Boggs A, Walzak K, Helbing CC. Exposure to tetrabromobisphenol-A alters TH-associated gene expression and tadpole metamorphosis in the Pacific tree frog Pseudacris regilla. Aquat Toxicol. (2006) 78:292-302. doi: 10.1016/j.aquatox.2006.04.002

76. Jagnytsch O, Opitz R, Lutz I, Kloas W. Effects of tetrabromobisphenol A on larval development and thyroid hormone-regulated biomarkers of the amphibian Xenopus laevis. Environ Res. (2006) 101:340-8. doi: 10.1016/j.envres.2005.09.006

77. Fini J-B, Riu A, Debrauwer L, Hillenweck A, Le Mével S, Chevolleau S, et al. Parallel biotransformation of tetrabromobisphenol A in Xenopus laevis and Mammals: Xenopus as a model for endocrine perturbation studies. Toxicol Sci. (2012) 125:359-67. doi: 10.1093/toxsci/kfr312

78. Mengeling BJ, Wei Y, Dobrawa LN, Streekstra M, Louisse J, Singh V, et al. A multi-tiered, in vivo, quantitative assay suite for environmental disruptors of thyroid hormone signaling. Aquat Toxicol Amst Neth. (2017) 190:110. doi: 10.1016/j.aquatox.2017.06.019

79. Wang Y, Li Y, Qin Z, Wei W. Re-evaluation of thyroid hormone signaling antagonism of tetrabromobisphenol A for validating the $T_{3}$ induced Xenopus metamorphosis assay. J Environ Sci China. (2017) 52:32532. doi: 10.1016/j.jes.2016.09.021

80. Zhang Y-F, Xu W, Lou Q-Q, Li Y-Y, Zhao Y-X, Wei W-J, et al. Tetrabromobisphenol A disrupts vertebrate development via thyroid hormone signaling pathway in a developmental stage-dependent manner. Environ Sci Technol. (2014) 48:8227-34. doi: 10.1021/es502366g

81. Hinther A, Domanski D, Vawda S, Helbing CC. C-fin: a cultured frog tadpole tail fin biopsy approach for detection of thyroid hormone-disrupting chemicals. Environ Toxicol Chem. (2010) 29:380-8. doi: 10.1002/etc.44

82. Ji L, Domanski D, Skirrow RC, Helbing CC. Genistein prevents thyroid hormone-dependent tail regression of Rana catesbeiana tadpoles by targetting protein kinase $\mathrm{C}$ and thyroid hormone receptor $\alpha$. Dev Dyn. (2007) 236:777-90. doi: 10.1002/dvdy.21088

83. Sun N, Wang H, Ju Z, Zhao H. Effects of chronic cadmium exposure on metamorphosis, skeletal development, and thyroid endocrine disruption in Chinese toad Bufo gargarizans tadpoles. Environ Toxicol Chem. (2018) 37:213-23. doi: 10.1002/etc.3947

84. Hinther A, Vawda S, Skirrow RC, Veldhoen N, Collins P, Cullen JT, et al. Nanometals induce stress and alter thyroid hormone action in amphibia at or below North American water quality guidelines. Environ Sci Technol. (2010) 44:8314-21. doi: 10.1021/es101902n

85. Wang C, Liang G, Chai L, Wang H. Effects of copper on growth, metamorphosis and endocrine disruption of Bufo gargarizans larvae. Aquat Toxicol Amst Neth. (2016) 170:24-30. doi: 10.1016/j.aquatox.2015.10.023

86. Shi Q, Sun N, Kou H, Wang H, Zhao H. Chronic effects of mercury on Bufo gargarizans larvae: Thyroid disruption, liver damage, oxidative stress and lipid metabolism disorder. Ecotoxicol Environ Saf. (2018) 164:5009. doi: 10.1016/j.ecoenv.2018.08.058

87. Carew AC, Hoque ME, Metcalfe CD, Peyrot C, Wilkinson KJ, Helbing CC. Chronic sublethal exposure to silver nanoparticles disrupts thyroid hormone signaling during Xenopus laevis metamorphosis. Aquat Toxicol Amst Neth. (2015) 159:99-108. doi: 10.1016/j.aquatox.2014.12.005

88. Helbing CC, Ovaska K, Ji L. Evaluation of the effect of acetochlor on thyroid hormone receptor gene expression in the brain and behavior of Rana catesbeiana tadpoles. Aquat Toxicol Amst Neth. (2006) 80:4251. doi: 10.1016/j.aquatox.2006.07.011

89. Veldhoen N, Helbing CC. Detection of environmental endocrine-disruptor effects on gene expression in live Rana catesbeiana tadpoles using a tail fin biopsy technique. Environ Toxicol Chem. (2001) 20:2704-8. doi: $10.1002 /$ etc. 5620201208

90. Crump D, Werry K, Veldhoen N, Van Aggelen G, Helbing CC. Exposure to the herbicide acetochlor alters thyroid hormone-dependent gene expression and metamorphosis in Xenopus laevis. Environ Health Perspect. (2002) 110:1199-205. doi: 10.1289/ehp.021101199

91. Boone MD, Hammond SA, Veldhoen N, Youngquist M, Helbing CC. Specific time of exposure during tadpole development influences biological effects of the insecticide carbaryl in green frogs (Lithobates clamitans). Aquat Toxicol. (2013) 130-131:139-48. doi: 10.1016/j.aquatox.2012.12.022
92. Howe CM, Berrill M, Pauli BD, Helbing CC, Werry K, Veldhoen N. Toxicity of glyphosate-based pesticides to four North American frog species. Environ Toxicol Chem. (2004) 23:1928-38. doi: 10.1897/03-71

93. Iwamuro S, Sakakibara M, Terao M, Ozawa A, Kurobe C, Shigeura $\mathrm{T}$, et al. Teratogenic and anti-metamorphic effects of bisphenol $\mathrm{A}$ on embryonic and larval Xenopus laevis. Gen Comp Endocrinol. (2003) 133:18998. doi: 10.1016/S0016-6480(03)00188-6

94. Heimeier RA, Das B, Buchholz DR, Shi Y-B. The xenoestrogen bisphenol A inhibits postembryonic vertebrate development by antagonizing gene regulation by thyroid hormone. Endocrinology. (2009) 150:2964-73. doi: 10.1210/en.2008-1503

95. Sugiyama S, Shimada N, Miyoshi H, Yamauchi K. Detection of thyroid system-disrupting chemicals using in vitro and in vivo screening assays in Xenopus laevis. Toxicol Sci. (2005) 88:367-74. doi: 10.1093/toxsci/kfi330

96. Shen O, Wu W, Du G, Liu R, Yu L, Sun H, et al. Thyroid disruption by di-nbutyl phthalate (DBP) and mono-n-butyl phthalate (MBP) in Xenopus laevis. PLoS ONE. (2011) 6:0019159. doi: 10.1371/journal.pone.0019159

97. Dasgupta PK, Dyke JV, Kirk AB, Jackson WA. Perchlorate in the United States. Analysis of relative source contributions to the food chain. Environ Sci Technol. (2006) 40:6608-14. doi: 10.1021/es061321z

98. Leung AM, Pearce EN, Braverman LE. Perchlorate, iodine and the thyroid. Best Pract Res Clin Endocrinol Metab. (2010) 24:133-41. doi: 10.1016/j.beem.2009.08.009

99. Tonacchera M, Pinchera A, Dimida A, Ferrarini E, Agretti P, Vitti P, et al. Relative potencies and additivity of perchlorate, thiocyanate, nitrate, and iodide on the inhibition of radioactive iodide uptake by the human sodium iodide symporter. Thyroid. (2004) 14:1012-9. doi: 10.1089/thy.2004.14.1012

100. Carr JA, Theodorakis C. Effects of perchlorate in amphibians. In: Kendall RJ, Smith PN, editors. Perchlorate Ecotoxicology (Pensacola: SETAC Press), p. 125-53.

101. Goleman WL, Carr JA, Anderson TA. Environmentally relevant concentrations of ammonium perchlorate inhibit thyroid function and alter sex ratios in developing Xenopus laevis. Environ Toxicol Chem. (2002) 21:590-7. doi: 10.1002/etc.5620210318

102. Goleman WL, Urquidi LJ, Anderson TA, Smith EE, Kendall RJ, Carr JA. Environmentally relevant concentrations of ammonium perchlorate inhibit development and metamorphosis in Xenopus laevis. Environ Toxicol Chem. (2002) 21:424-30. doi: 10.1002/etc.5620210227

103. Ruthsatz K, Dausmann KH, Drees C, Becker LI, Hartmann L, Reese J, et al. Altered thyroid hormone levels affect body condition at metamorphosis in larvae of Xenopus laevis. J Appl Toxicol. (2018) 38:141625. doi: 10.1002 /jat.3663

104. Tietge JE, Butterworth BC, Haselman JT, Holcombe GW, Hornung MW, Korte JJ, et al. Early temporal effects of three thyroid hormone synthesis inhibitors in Xenopus laevis. Aquat Toxicol. (2010) 98:4450. doi: 10.1016/j.aquatox.2010.01.014

105. Hornung MW, Degitz SJ, Korte LM, Olson JM, Kosian PA, Linnum AL, et al. Inhibition of thyroid hormone release from cultured amphibian thyroid glands by methimazole, 6-propylthiouracil, and perchlorate. Toxicol Sci. (2010) 118:42-51. doi: 10.1093/toxsci/kfq166

106. Opitz R. Expression of sodium-iodide symporter mRNA in the thyroid gland of Xenopus laevis tadpoles: developmental expression, effects of antithyroidal compounds, and regulation by TSH. J Endocrinol. (2006) 190:157-70. doi: 10.1677/joe.1.06606

107. Tietge JE, Holcombe GW, Flynn KM, Kosian PA, Korte JJ, Anderson LE, et al. Metamorphic inhibition of Xenopus laevis by sodium perchlorate: effects on development and thyroid histology. Environ Toxicol Chem. (2005) 24:926-33. doi: 10.1897/04-105R.1

108. Flood DEK, Langlois VS. Crosstalk between the thyroid hormone and androgen axes during reproductive development in Silurana tropicalis. Gen Comp Endocrinol. (2014) 203:232-40. doi: 10.1016/j.ygcen.2014. 03.037

109. Alaee M, Arias P, Sjödin A, Bergman A. An overview of commercially used brominated flame retardants, their applications, their use patterns in different countries/regions and possible modes of release. Environ Int. (2003) 29:683-9. doi: 10.1016/S0160-4120(03)00121-1

110. Hendriks HS, Westerink RHS. Neurotoxicity and risk assessment of brominated and alternative flame retardants. 
Neurotoxicol Teratol. (2015) 52:248-69. doi: 10.1016/j.ntt.2015. 09.002

111. Birnbaum LS, Staskal DF. Brominated flame retardants: cause for concern? Environ Health Perspect. (2004) 112:9-17. doi: 10.1289/ehp.6559

112. de Wit CA. An overview of brominated flame retardants in the environment. Chemosphere. (2002) 46:583-624. doi: 10.1016/S0045-6535(01)00225-9

113. Covaci A, Harrad S, Abdallah MA-E, Ali N, Law RJ, Herzke $\mathrm{D}$, et al. Novel brominated flame retardants: a review of their analysis, environmental fate and behaviour. Environ Int. (2011) 37:532-56. doi: 10.1016/j.envint.2010.11.007

114. Cary TL, Karasov WH. Toxicokinetics of polybrominated diphenyl ethers across life stages in the northern leopard frog (Lithobates pipiens). Environ Toxicol Chem. (2013) 32:1631-40. doi: 10.1002/etc.2215

115. Coyle TLC, Karasov WH. Chronic, dietary polybrominated diphenyl ether exposure affects survival, growth, and development of Rana pipiens tadpoles. Environ Toxicol Chem. (2010) 29:133-41. doi: 10.1002/etc.21

116. Liu P-Y, Du G-D, Zhao Y-X, Mu Y-S, Zhang A-Q, Qin Z$F$, et al. Bioaccumulation, maternal transfer and elimination of polybrominated diphenyl ethers in wild frogs. Chemosphere. (2011) 84:972-8. doi: 10.1016/j.chemosphere.2011.05.042

117. Carlsson G, Kulkarni P, Larsson P, Norrgren L. Distribution of BDE-99 and effects on metamorphosis of BDE-99 and-47 after oral exposure in Xenopus tropicalis. Aquat Toxicol. (2007) 84:71-9. doi: 10.1016/j.aquatox.2007.06.003

118. Lai DY, Kacew S, Dekant W. Tetrabromobisphenol A (TBBPA): possible modes of action of toxicity and carcinogenicity in rodents. Food Chem Toxicol. (2015) 80:206-14. doi: 10.1016/j.fct.2015.03.023

119. Sellström U, Jansson B. Analysis of tetrabromobisphenol A in a product and environmental samples. Chemosphere. (1995) 31:308592. doi: 10.1016/0045-6535(95)00167-7

120. Kuester RK, Sólyom AM, Rodriguez VP, Sipes IG. The effects of dose, route, and repeated dosing on the disposition and kinetics of tetrabromobisphenol A in male F-344 rats. Toxicol Sci Off J Soc Toxicol. (2007) 96:23745. doi: 10.1093/toxsci/kfm006

121. Cariou R, Antignac J-P, Zalko D, Berrebi A, Cravedi J-P, Maume D, et al. Exposure assessment of French women and their newborns to tetrabromobisphenol-A: occurrence measurements in maternal adipose tissue, serum, breast milk and cord serum. Chemosphere. (2008) 73:103641. doi: 10.1016/j.chemosphere.2008.07.084

122. Meerts IA, van Zanden JJ, Luijks EA, van Leeuwen-Bol I, Marsh G, Jakobsson E, et al. Potent competitive interactions of some brominated flame retardants and related compounds with human transthyretin in vitro. Toxicol Sci OffJ Soc Toxicol. (2000) 56:95-104.

123. Kitamura S, Kato T, Iida M, Jinno N, Suzuki T, Ohta S, et al. Antithyroid hormonal activity of tetrabromobisphenol A, a flame retardant, and related compounds: affinity to the mammalian thyroid hormone receptor, and effect on tadpole metamorphosis. Life Sci. (2005) 76:1589601. doi: 10.1016/j.lfs.2004.08.030

124. Freeman JL, Beccue N, Rayburn AL. Differential metamorphosis alters the endocrine response in anuran larvae exposed to $\mathrm{T}_{3}$ and atrazine. Aquat Toxicol. (2005) 75:263-76. doi: 10.1016/j.aquatox.2005.08.012

125. Jung J-C, Leco KJ, Edwards DR, Fini ME. Matrix metalloproteinases mediate the dismantling of mesenchymal structures in the tadpole tail during thyroid hormone-induced tail resorption. Dev Dyn. (2002) 223:40213. doi: 10.1002/dvdy.10069

126. Tyl RW. Abbreviated assessment of bisphenol A toxicology literature. Semin Fetal Neonatal Med. (2014) 19:195-202. doi: 10.1016/j.siny.2013.11.010

127. Tudurí E, Marroqui L, Dos Santos RS, Quesada I, Fuentes E, AlonsoMagdalena P. Timing of exposure and bisphenol-A: implications for diabetes development. Front Endocrinol. (2018) 9:648. doi: 10.3389/fendo.2018. 00648

128. Legeay S, Faure S. Is bisphenol A an environmental obesogen? Fundam Clin Pharmacol. (2017) 31:594-609. doi: 10.1111/fcp.12300

129. Gore AC, Krishnan K, Reilly MP. Endocrine-disrupting chemicals: effects on neuroendocrine systems and the neurobiology of social behavior. Horm Behav. (2018) doi: 10.1016/j.yhbeh.2018.11.006. [Epub ahead of print].

130. Gramec Skledar D, Peterlin Mašič L. Bisphenol A and its analogs: do their metabolites have endocrine activity? Environ Toxicol Pharmacol. (2016) 47:182-99. doi: 10.1016/j.etap.2016.09.014
131. Heimeier RA, Shi Y-B. Amphibian metamorphosis as a model for studying endocrine disruption on vertebrate development: Effect of bisphenol A on thyroid hormone action. Gen Comp Endocrinol. (2010) 168:1819. doi: 10.1016/j.ygcen.2010.02.016

132. Fukutake M, Takahashi M, Ishida K, Kawamura H, Sugimura T, Wakabayashi K. Quantification of genistein and genistin in soybeans and soybean products. Food Chem Toxicol. (1996) 34:457-61. doi: 10.1016/0278-6915(96)87355-8

133. Henley DV, Korach KS. Endocrine-disrupting chemicals use distinct mechanisms of action to modulate endocrine system function. Endocrinology. (2006) 147:s25-32. doi: 10.1210/en.2005-1117

134. Akiyama T, Ishida J, Nakagawa S, Ogawara H, Watanabe S, Itoh $\mathrm{N}$, et al. Genistein, a specific inhibitor of tyrosine-specific protein kinases. J Biol Chem. (1987) 262:5592-5.

135. Li W, Mischak H, Yu JC, Wang LM, Mushinski JF, Heidaran MA, et al. Tyrosine phosphorylation of protein kinase C-delta in response to its activation. J Biol Chem. (1994) 269:2349-52.

136. Doerge DR, Sheehan DM. Goitrogenic and estrogenic activity of soy isoflavones. Environ Health Perspect. (2002) 110(Suppl. 3):349-53. doi: 10.1289/ehp.02110s3349

137. Weschler CJ, Nazaroff WW. Semivolatile organic compounds in indoor environments. Atmos Environ. (2008) 42:901840. doi: 10.1016/j.atmosenv.2008.09.052

138. Zhang Z-M, Zhang H-H, Zhang J, Wang Q-W, Yang G-P. Occurrence, distribution, and ecological risks of phthalate esters in the seawater and sediment of Changjiang River Estuary and its adjacent area. Sci Total Environ. (2018) 619-620:93-102. doi: 10.1016/j.scitotenv.2017.11.070

139. Vitali M. Phthalate esters in freshwaters as markers of contamination sources-a site study in Italy. Environ Int. (1997) 23:337-47. doi: 10.1016/S0160-4120(97)00035-4

140. Mathieu-Denoncourt J, Wallace SJ, de Solla SR, Langlois VS. Plasticizer endocrine disruption: highlighting developmental and reproductive effects in mammals and non-mammalian aquatic species. Gen Comp Endocrinol. (2015) 219:74-88. doi: 10.1016/j.ygcen.2014.11.003

141. Shen O, Du G, Sun H, Wu W, Jiang Y, Song L, et al. Comparison of in vitro hormone activities of selected phthalates using reporter gene assays. Toxicol Lett. (2009) 191:9-14. doi: 10.1016/j.toxlet.2009.07.019

142. Mathieu-Denoncourt J, de Solla SR, Langlois VS. Chronic exposures to monomethyl phthalate in Western clawed frogs. Gen Comp Endocrinol. (2015) 219:53-63. doi: 10.1016/j.ygcen.2015.01.019

143. Wu X, Cobbina SJ, Mao G, Xu H, Zhang Z, Yang L. A review of toxicity and mechanisms of individual and mixtures of heavy metals in the environment. Environ Sci Pollut Res. (2016) 23:8244-59. doi: 10.1007/s11356-016-6333-x

144. James SM, Little EE. The effects of chronic cadmium exposure on American toad (Bufo americanus) tadpoles. Environ Toxicol Chem. (2003) 22:377-80. doi: 10.1002/etc.5620220219

145. Flament S, Kuntz S, Chesnel A, Grillier-Vuissoz I, Tankozic C, Penrad-Mobayed $\mathrm{M}$, et al. Effect of cadmium on gonadogenesis and metamorphosis in Pleurodeles walt (urodele amphibian). Aquat Toxicol Amst Neth. (2003) 64:143-53. doi: 10.1016/S0166-445X(03)00042-0

146. Sharma B, Patiño R. Effects of cadmium on growth, metamorphosis and gonadal sex differentiation in tadpoles of the African clawed frog, Xenopus laevis. Chemosphere. (2009) 76:104855. doi: 10.1016/j.chemosphere.2009.04.043

147. Sharma B, Patiño R. Effects of cadmium, estradiol-17beta and their interaction on gonadal condition and metamorphosis of male and female African clawed frog, Xenopus laevis. Chemosphere. (2010) 79:499505. doi: 10.1016/j.chemosphere.2010.02.044

148. Chen T-H, Gross JA, Karasov WH. Adverse effects of chronic copper exposure in larval northern leopard frogs (Rana pipiens). Environ Toxicol Chem. (2007) 26:1470-5. doi: 10.1897/06-487R.1

149. Peles JD. Effects of chronic aluminum and copper exposure on growth and development of wood frog (Rana sylvatica) larvae. Aquat Toxicol Amst Neth. (2013) 140-141:242-8. doi: 10.1016/j.aquatox.2013.06.009

150. Veronez AC da S, Salla RV, Baroni VD, Barcarolli IF, Bianchini A, dos Reis Martinez CB, et al. Genetic and biochemical effects induced by iron ore, Fe and $\mathrm{Mn}$ exposure in tadpoles of the bullfrog Lithobates catesbeianus. Aquat Toxicol. (2016) 174:101-8. doi: 10.1016/j.aquatox.2016.02.011 
151. Chen T-H, Gross JA, Karasov WH. Sublethal effects of lead on northern leopard frog (Rana pipiens) tadpoles. Environ Toxicol Chem. (2006) 25:13839. doi: 10.1897/05-356R.1

152. Mitchell SE, Caldwell CA, Gonzales G, Gould WR, Arimoto R. Effects of depleted uranium on survival, growth, and metamorphosis in the African clawed frog (Xenopus laevis). J Toxicol Environ Health A. (2005) 68:951-65. doi: 10.1080/1528739059091 2595

153. Iavicoli I, Fontana L, Leso V, Bergamaschi A. The effects of nanomaterials as endocrine disruptors. Int J Mol Sci. (2013) 14:16732-801. doi: 10.3390/ijms140816732

154. Shaw BJ, Handy RD. Physiological effects of nanoparticles on fish: a comparison of nanometals versus metal ions. Environ Int. (2011) 37:108397. doi: 10.1016/j.envint.2011.03.009

155. Nations S, Wages M, Cañas JE, Maul J, Theodorakis C, Cobb GP. Acute effects of $\mathrm{Fe}$ ?O ?, TiO?, $\mathrm{ZnO}$ and $\mathrm{CuO}$ nanomaterials on Xenopus laevis. Chemosphere. (2011) 83:1053-61. doi: 10.1016/j.chemosphere.2011.01.061

156. Nations S, Long M, Wages M, Canas J, Maul JD, Theodorakis C, Cobb GP. Effects of $\mathrm{ZnO}$ nanomaterials on Xenopus laevis growth and development. Ecotoxicol Environ Saf. (2011) 74:203-10. doi: 10.1016/j.ecoenv.2010.07.018

157. Nations S, Long M, Wages M, Maul JD, Theodorakis CW, Cobb GP. Subchronic and chronic developmental effects of copper oxide (CuO) nanoparticles on Xenopus laevis. Chemosphere. (2015) 135:16674. doi: 10.1016/j.chemosphere.2015.03.078

158. Zhang J, Wages M, Cox SB, Maul JD, Li Y, Barnes M, et al. Effect of titanium dioxide nanomaterials and ultraviolet light coexposure on African clawed frogs (Xenopus laevis). Environ Toxicol Chem. (2012) 31:17683. doi: $10.1002 /$ etc.718

159. Hammond SA, Carew AC, Helbing CC. Evaluation of the effects of titanium dioxide nanoparticles on cultured Rana catesbeiana tailfin tissue. Front Genet. (2013) 4:251. doi: 10.3389/fgene.2013.00251

160. Fong PP, Thompson LB, Carfagno GLF, Sitton AJ. Long-term exposure to gold nanoparticles accelerates larval metamorphosis without affecting mass in wood frogs (Lithobates sylvaticus) at environmentally relevant concentrations. Environ Toxicol Chem. (2016) 35:2304-10. doi: 10.1002/etc.3396

161. Arregui MC, Sánchez D, Althaus R, Scotta RR, Bertolaccini I. Assessing the risk of pesticide environmental impact in several Argentinian cropping systems with a fuzzy expert indicator. Pest Manag Sci. (2010) 66:73640. doi: 10.1002/ps.1935

162. Barbash JE, Thelin GP, Kolpin DW, Gilliom RJ. Major herbicides in ground water: results from the National Water-Quality Assessment. J Environ Qual. (2001) 30:831-45. doi: 10.2134/jeq2001.303831x

163. Scribner EA, Battaglin WA, Goolsby DA, Thurman EM. Changes in herbicide concentrations in Midwestern streams in relation to changes in use, 1989-1998. Sci Total Environ. (2000) 248:255-63. doi: 10.1016/S0048-9697(99)00547-1

164. Li W, Zha J, Li Z, Yang L, Wang Z. Effects of exposure to acetochlor on the expression of thyroid hormone related genes in larval and adult rare minnow (Gobiocypris rarus). Aquat Toxicol Amst Neth. (2009) 94:8793. doi: 10.1016/j.aquatox.2009.06.002

165. Liu $\mathrm{H}$, Chu T, Chen L, Gui W, Zhu G. In vivo cardiovascular toxicity induced by acetochlor in zebrafish larvae. Chemosphere. (2017) 181:6008. doi: 10.1016/j.chemosphere.2017.04.090

166. Yang M, Hu J, Li S, Ma Y, Gui W, Zhu G. Thyroid endocrine disruption of acetochlor on zebrafish (Danio rerio) larvae. J Appl Toxicol JAT. (2016) 36:844-52. doi: 10.1002/jat.3230

167. Ali JM, Sangster JL, Snow DD, Bartelt-Hunt SL, Kolok AS. Compensatory response of fathead minnow larvae following a pulsed in-situ exposure to a seasonal agricultural runoff event. Sci Total Environ. (2017) 603-4:81726. doi: 10.1016/j.scitotenv.2017.03.093

168. Buck JC, Hua J, Brogan WR, Dang TD, Urbina J, Bendis RJ, et al. Effects of pesticide mixtures on host-pathogen dynamics of the amphibian chytrid fungus. PLoS ONE. (2015) 10:e0132832. doi: 10.1371/journal.pone.01 32832

169. Cheek AO, Ide CF, Bollinger JE, Rider CV, McLachlan JA. Alteration of leopard frog (Rana pipiens) metamorphosis by the herbicide acetochlor. Arch Environ Contam Toxicol. (1999) 37:70-7.
170. Gunasekara AS, Rubin AL, Goh KS, Spurlock FC, Tjeerdema RS, Environmental fate and toxicology of carbaryl. Rev Environ Contam Toxicol. (2008) 196:95-121. doi: 10.1007/978-0-387-78444-1_4

171. Silberman J, Taylor A. Carbamate Toxicity. In: StatPearls. Treasure Island FL: StatPearls Publishing. Available online at: http://www.ncbi.nlm.nih.gov/ books/NBK482183/ (accessed December 6, 2018).

172. Rosman Y, Makarovsky I, Bentur Y, Shrot S, Dushnistky T, Krivoy A. Carbamate poisoning: treatment recommendations in the setting of a mass casualties event. Am J Emerg Med. (2009) 27:1117-24. doi: 10.1016/j.ajem.2009.01.035

173. Pochini KM, Hoverman JT. Reciprocal effects of pesticides and pathogens on amphibian hosts: The importance of exposure order and timing. Environ Pollut Barking Essex 1987. (2017) 221:359-66. doi: 10.1016/j.envpol.2016.11.086

174. Pochini KM, Hoverman JT. Immediate and lag effects of pesticide exposure on parasite resistance in larval amphibians. Parasitology. (2017) 144:81722. doi: 10.1017/S0031182016002560

175. Boone MD. An amphibian with a contracting range is not more vulnerable to pesticides in outdoor experimental communities than common species. Environ Toxicol Chem. (2018) 37:2699-704. doi: 10.1002/etc.4236

176. Perkins PJ, Boermans HJ, Stephenson GR. Toxicity of glyphosate and triclopyr using the frog embryo teratogenesis assay-Xenopus. Environ Toxicol Chem. (2000) 19:940-5. doi: 10.1002/etc.5620190422

177. Giesy JP, Dobson S, Solomon KR. Ecotoxicological Risk Assessment for Roundup $\mathbb{R}$ Herbicide. In: Ware GW, editor. Reviews of Environmental Contamination and Toxicology: Continuation of Residue Reviews Reviews of Environmental Contamination and Toxicology. New York, NY: Springer New York, 35-120.

178. Chen H, Liu Z, Zhang X, Jia X, Li Q, Su Q, et al. Assessment of synergistic thyroid disrupting effects of a mixture of EDCs in ovariectomized rats using factorial analysis and dose addition. Toxicol Res. (2016) 5:158593. doi: 10.1039/c6tx00193a

179. Lefcort H, Meguire RA, Wilson LH, Ettinger WF. Heavy metals alter the survival, growth, metamorphosis, and antipredatory behavior of columbia spotted frog (Rana luteiventris) tadpoles. Arch Environ Contam Toxicol. (1998) 35:447-56. doi: 10.1007/s002449900401

180. Dorchin A, Shanas U. Assessment of pollution in road runoff using a Bufo viridis biological assay. Environ Pollut. (2010) 158:3626-33. doi: 10.1016/j.envpol.2010.08.004

181. Truter JC, Wyk JH van, Oberholster PJ, Botha A-M, Mokwena LM. An evaluation of the endocrine disruptive potential of crude oil water accommodated fractions and crude oil contaminated surface water to freshwater organisms using in vitro and in vivo approaches. Environ Toxicol Chem. (2017) 36:1330-42. doi: 10.1002/etc.3665

182. Wojnarowicz P, Ogunlaja OO, Xia C, Parker WJ, Helbing CC. Impact of wastewater treatment configuration and seasonal conditions on thyroid hormone disruption and stress effects in Rana catesbeiana tailfin. Environ Sci Technol. (2013) 47:13840-7. doi: 10.1021/es403767y

183. Wojnarowicz P, Yang W, Zhou H, Parker WJ, Helbing CC. Changes in hormone and stress-inducing activities of municipal wastewater in a conventional activated sludge wastewater treatment plant. Water Res. (2014) 66:265-72. doi: 10.1016/j.watres.2014.08.035

184. Searcy BT, Beckstrom-Sternberg SM, Beckstrom-Sternberg JS, Stafford P, Schwendiman AL, Soto-Pena J, et al. Thyroid hormone-dependent development in Xenopus laevis: a sensitive screen of thyroid hormone signaling disruption by municipal wastewater treatment plant effluent. Gen Comp Endocrinol. (2012) 176:481-92. doi: 10.1016/j.ygcen.2011.12.036

185. Lanctôt C, Bennett W, Wilson S, Fabbro L, Leusch FDL, Melvin SD. Behaviour, development and metal accumulation in striped marsh frog tadpoles (Limnodynastes peronii) exposed to coal mine wastewater. Aquat Toxicol Amst Neth. (2016) 173:218-27. doi: 10.1016/j.aquatox.2016.01.014

186. Sowers AD, Mills MA, Klaine SJ. The developmental effects of a municipal wastewater effluent on the northern leopard frog, Rana pipiens. Aquat Toxicol Amst Neth. (2009) 94:145-52. doi: 10.1016/j.aquatox.2009.06.013

187. Ruiz AM, Maerz JC, Davis AK, Keel MK, Ferreira AR, Conroy MJ, et al. Patterns of development and abnormalities among tadpoles in a constructed wetland receiving treated wastewater. Environ Sci Technol. (2010) 44:48628. doi: 10.1021/es903785x 
188. Castillo L, Seriki K, Mateos S, Loire N, Guédon N, Lemkine GF, et al. In vivo endocrine disruption assessment of wastewater treatment plant effluents with small organisms. Water Sci Technol J Int Assoc Water Pollut Res. (2013) 68:261-8. doi: 10.2166/wst.2013.179

189. Fraser B. Oil in the forest. Science. (2016) 353:6413. doi: 10.1126/science.353.6300.641

190. Wan Y, Wang B, Khim JS, Hong S, Shim WJ, Hu J. Naphthenic acids in coastal sediments after the Hebei Spirit oil spill: A potential indicator for oil contamination. Environ Sci Technol. (2014) 48:415362. doi: 10.1021/es405034y

191. Olson GM, Meyer BM, Portier RJ. Assessment of the toxic potential of polycyclic aromatic hydrocarbons (PAHs) affecting Gulf menhaden (Brevoortia patronus) harvested from waters impacted by the BP Deepwater Horizon Spill. Chemosphere. (2016) 145:322-8. doi: 10.1016/j.chemosphere.2015.11.087

192. Melvin SD, Trudeau VL. Growth, development and incidence of deformities in amphibian larvae exposed as embryos to naphthenic acid concentrations detected in the Canadian oil sands region. Environ Pollut. (2012) 167:17883. doi: 10.1016/j.envpol.2012.04.002

193. Bryer PJ, Elliott JN, Willingham EJ. The effects of coal tar based pavement sealer on amphibian development and metamorphosis. Ecotoxicology. (2006) 15:241-7. doi: 10.1007/s10646-005-0055-Z

194. Hersikorn BD, Smits JEG. Compromised metamorphosis and thyroid hormone changes in wood frogs (Lithobates sylvaticus) raised on reclaimed wetlands on the Athabasca oil sands. Environ Pollut Barking Essex 1987. (2011) 159:596-601. doi: 10.1016/j.envpol.2010.10.005

195. Freitas JS, Kupsco A, Diamante G, Felicio AA, Almeida EA, Schlenk D. Influence of temperature on the thyroidogenic effects of diuron and its metabolite 3,4-DCA in tadpoles of the American bullfrog (Lithobates catesbeianus). Environ Sci Technol. (2016) 50:13095-104. doi: 10.1021/acs.est.6b04076

196. Freitas MB, Brown CT, Karasov WH. Warmer temperature modifies effects of polybrominated diphenyl ethers on hormone profiles in leopard frog tadpoles (Lithobates pipiens). Environ Toxicol Chem. (2017) 36:1207. doi: $10.1002 /$ etc. 3506

197. Hayes T, Chan R, Licht P. Interactions of temperature and steroids on larval growth, development, and metamorphosis in a toad (Bufo boreas). J Exp Zool. (1993) 266:206-15. doi: 10.1002/jez.1402660306

198. O’Regan SM, Palen WJ, Anderson SC. Climate warming mediates negative impacts of rapid pond drying for three amphibian species. Ecology. (2014) 95:845-55. doi: 10.1890/13-0916.1

199. Gomez-Mestre I, Kulkarni S, Buchholz DR. Mechanisms and consequences of developmental acceleration in tadpoles responding to pond drying. PLoS ONE. (2013) 8:0084266. doi: 10.1371/journal.pone.008 4266

200. Johansson F, Veldhoen N, Lind MI, Helbing CC. Phenotypic plasticity in the hepatic transcriptome of the European common frog (Rana temporaria): the interplay between environmental induction and geographical lineage on developmental response. Mol Ecol. (2013) 22:5608-23. doi: $10.1111 / \mathrm{mec} .12497$

201. Loman J. Early metamorphosis in common frog Rana temporaria tadpoles at risk of drying: an experimental demonstration. Amphibia Reptilia. (1999) 20:4 doi: 10.1163/156853899507176

202. Murata T, Yamauchi K. Low-temperature arrest of the triiodothyroninedependent transcription in Rana catesbeiana Red Blood Cells. Endocrinology. (2005) 146:256-64. doi: 10.1210/en.2004-1090

203. Suzuki S, Awai K, Ishihara A, Yamauchi K. Cold temperature blocks thyroid hormone-induced changes in lipid and energy metabolism in the liver of Lithobates catesbeianus tadpoles. Cell Biosci. (2016) 6:19-34. doi: 10.1186/s13578-016-0087-5

204. Mochizuki K, Goda T, Yamauchi K. Gene expression profile in the liver of Rana catesbeiana tadpoles exposed to low temperature in the presence of thyroid hormone. Biochem Biophys Res Commun. (2012) 420:84550. doi: 10.1016/j.bbrc.2012.03.085

205. Croteau MC, Davidson MA, Lean DRS, Trudeau VL. Global increases in ultraviolet B radiation: Potential impacts on amphibian development and metamorphosis. Physiol Biochem Zool. (2008) 81:743-61. doi: 10.1086/591949
206. Croteau MC, Davidson M, Duarte-Guterman P, Wade M, Popesku JT, Wiens $\mathrm{S}$, et al. Assessment of thyroid system disruption in Rana pipiens tadpoles chronically exposed to UVB radiation and 4-tert-octylphenol. Aquat Toxicol. (2009) 95:81-92. doi: 10.1016/j.aquatox.2009.05.013

207. Frieden E, Wahlborg A, Howard E. Temperature control of the response of tadpoles to triiodothyronine. Nature. (1965) 205:11736. doi: $10.1038 / 2051173 \mathrm{a} 0$

208. Fry AE. Effects of temperature on shortening of isolated Rana pipiens tadpole tail tips. J Exp Zool. (1972) 180:197-207. doi: 10.1002/jez.140180 0207

209. Austin Hammond S, Jackman KW, Partovi SH, Veldhoen N, Helbing CC. Identification of organ-autonomous constituents of the molecular memory conferred by thyroid hormone exposure in cold temperature-arrested metamorphosing Rana (Lithobates) catesbeiana tadpoles. Comp Biochem Physiol Part D Genomics Proteomics. (2016) 17:58-65. doi: 10.1016/j.cbd.2016.01.002

210. Hammond SA, Nelson CJ, Helbing CC. Environmental influences on the epigenomes of herpetofauna and fish. Biochem Cell Biol. (2016) 94:95100. doi: 10.1139/bcb-2015-0111

211. Dugo MA, Han F, Tchounwou PB. Persistent polar depletion of stratospheric ozone and emergent mechanisms of ultraviolet radiationmediated health dysregulation. Rev Environ Health. (2012) 27:10316. doi: 10.1515/reveh-2012-0026

212. Schindler DW, Curtis PJ, Parker BR, Stainton MP. Consequences of climate warming and lake acidification for UV-B penetration in North American boreal lakes. Nature. (1996) 379:705-8. doi: 10.1038/379705a0

213. Grant KP, Licht LE. Effects of ultraviolet radiation on life-history stages of anurans from Ontario, Canada. Can J Zool. (1995) 73:2292301. doi: 10.1139/z95-271

214. Pahkala M, Laurila A, Merilä J. Carry-over effects of ultraviolet-B radiation on larval fitness in Rana temporaria. Proc R Soc B Biol Sci. (2001) 268:1699706. doi: $10.1098 / \mathrm{rspb} .2001 .1725$

215. Wright ML. Melatonin, diel rhythms, and metamorphosis in anuran amphibians. Gen Comp Endocrinol. (2002) 126:251-4. doi: 10.1016/S0016-6480(02)00012-6

216. Eichler VB, Gray LS. The influence of environmental lighting on the growth and prometamorphic development of larval Rana pipiens. Dev Growth Differ. (1976) 18:177-82. doi: 10.1111/j.1440-169X.1976.0 0177.x

217. Edwards MLO, Pivorun EB. The effects of photoperiod and different dosages of melatonin on metamorphic rate and weight gain in Xenopus laevis tadpoles. Gen Comp Endocrinol. (1991) 81:28-38. doi: 10.1016/0016-6480(91)90122-M

218. Wright ML, Jorey T, Myers YM, Fieldstad ML, Paquette CM, Clark MB. Influence of photoperiod, day length, and feeding schedule on tadpole growth and development. Dev Growth Differ. (1988) 30: 315-23.

219. Wright ML, Blanchard LS, Jorey ST, Basso CA, Myers YM, Paquette CM. Metamorphic rate as a function of the light/dark cycle in Rana pipiens larvae. Comp Biochem Physiol A Physiol. (1990) 96:21520. doi: 10.1016/0300-9629(90)90068-4

220. Wright ML, Bruni NK. Influence of the photocycle and thermocycle on rhythms of plasma thyroxine and plasma and ocular melatonin in late metamorphic stages of the bullfrog tadpole, Rana catesbeiana. Comp Biochem Physiol A Mol Integr Physiol. (2004) 139:33-40. doi: 10.1016/j.cbpb.2004.06.012

221. Wright ML, Duffy JL, Guertin CJ, Alves CD, Szatkowski MC, Visconti RF. Developmental and diel changes in plasma thyroxine and plasma and ocular melatonin in the larval and juvenile bullfrog, Rana catesbeiana. Gen Comp Endocrinol. (2003) 130:120-8. doi: 10.1016/S0016-6480(02)0 0575-0

222. Newman RA. Adaptive plasticity in amphibian metamorphosis. BioScience. (1992) 42:671-8. doi: 10.2307/1312173

223. Crump ML. Effect of habitat drying on developmental time and size at metamorphosis in Hyla pseudopuma. Copeia. (1989) 1989:794. doi: 10.2307/1445521

224. Denver RJ. Hormonal correlates of environmentally induced metamorphosis in the western spadefoot toad, Scaphiopus hammondii. Gen Comp Endocrinol. (1998) 110:326-36. doi: 10.1006/gcen.1998.7082 
225. Denver RJ. Environmental stress as a developmental cue: corticotropinreleasing hormone is a proximate mediator of adaptive phenotypic plasticity in amphibian metamorphosis. Horm Behav. (1997) 31:169-79.

226. Denver RJ, Mirhadi N, Phillips M. Adaptive plasticity in amphibian metamorphosis: response of Scaphiopus hammondii tadpoles to habitat desiccation. Ecology. (1998) 79:1859-72. doi: 10.1890/00129658(1998)079[1859:APIAMR]2.0.CO;2

227. Rudolf VHW, Rödel M-O. Phenotypic plasticity and optimal timing of metamorphosis under uncertain time constraints. Evol Ecol. (2007) 21:12142. doi: 10.1007/s10682-006-0017-9

228. Nicieza AG. Interacting effects of predation risk and food availability on larval anuran behaviour and development. Oecologia. (2000) 123:497505. doi: 10.1007/s004420000343

229. Blouin MS. Comparing bivariate reaction norms among species: time and size at metamorphosis in three species of Hyla (Anura: Hylidae). Oecologia. (1992) 90:288-293. doi: 10.1007/BF00317188

230. Leips J, Travis J. Metamorphic responses to changing food levels in two species of hylid frogs. Ecology. (1994) 75:1345-56. doi: 10.2307/1937459

231. Newman RA. Effects of changing density and food level on metamorphosis of a desert amphibian, Scaphiopus couchii. Ecology. (1994) 75:108596. doi: 10.2307/1939432

232. D'Angelo SA, Gordon AS, Charipper HA. The role of the thyroid and pituitary glands in the anomalous effect of inanition on amphibian metamorphosis. J Exp Zool. (1941) 87:259-77. doi: 10.1002/jez.1400870206

233. Wright ML, Proctor KL, Alves CD. Hormonal profiles correlated with season, cold, and starvation in Rana catesbeiana (bullfrog) tadpoles. Comp Biochem Physiol C Pharmacol Toxicol Endocrinol. (1999) 124:10916. doi: 10.1016/S0742-8413(99)00060-2

234. Boorse GC, Denver RJ. Endocrine mechanisms underlying plasticity in metamorphic timing in spadefoot toads. Integr Comp Biol. (2003) 43:646-57. doi: 10.1093/icb/43.5.646

235. Blaustein AR, Romansic JM, Kiesecker JM, Hatch AC. Ultraviolet radiation, toxic chemicals and amphibian population declines. Divers Distrib. (2003) 9:123-140. doi: 10.1046/j.1472-4642.2003.00015.x

236. Crump D, Lean D, Trudeau VL. Octylphenol and UV-B radiation alter larval development and hypothalamic gene expression in the leopard frog (Rana pipiens). Environ Health Perspect. (2002) 110:277-84. doi: 10.1289/ehp.02110277

237. Pickford DB. Screening chemicals for thyroid-disrupting activity: a critical comparison of mammalian and amphibian models. Crit Rev Toxicol. (2010) 40:845-92. doi: 10.3109/10408444.2010.494250

238. Fort DJ, Mathis MB, Pawlowski S, Wolf JC, Peter R, Champ S. Effect of triclosan on anuran development and growth in a larval amphibian growth and development assay. J Appl Toxicol. (2017) 37:118294. doi: $10.1002 /$ jat. 3474

239. Veldhoen N, Stevenson MR, Helbing CC. Comparison of thyroid hormonedependent gene responses in vivo and in organ culture of the American bullfrog (Rana (Lithobates) catesbeiana) lung. Comp Biochem Physiol Part D Genomics Proteomics. (2015) 16:99-105. doi: 10.1016/j.cbd.2015.09.001

240. Hinther A, Edwards TM, Guillette LJJ, Helbing C. Influence of nitrate and nitrite on thyroid hormone responsive and stress-associated gene expression in cultured Rana catesbeiana tadpole tail fin tissue. Front Genet. (2012) 3:51. doi: 10.3389/fgene.2012.00051

241. Eggert C. Sex determination: the amphibian models. Reprod Nutr Dev. (2004) 44:539-49. doi: 10.1051/rnd:2004062

242. Veldhoen N, Skirrow RC, Ji L, Domanski D, Bonfield ER, Bailey CM, et al. Use of heterologous cDNA arrays and organ culture in the detection of thyroid hormone-dependent responses in a sentinel frog, Rana catesbeiana. Comp Biochem Physiol Part D Genomics Proteomics. (2006) 1:187-99. doi: 10.1016/j.cbd.2005.10.005

243. Mughal BB, Leemans M, Spirhanzlova P, Demeneix B, Fini J-B. Reference gene identification and validation for quantitative realtime PCR studies in developing Xenopus laevis. Sci Rep. (2018) 8: 496-504 doi: 10.1038/s41598-017-18684-1

244. Van Aggelen G, Ankley GT, Baldwin WS, Bearden DW, Benson $\mathrm{WH}$, Chipman $\mathrm{JK}$, et al. Integrating omic technologies into aquatic ecological risk assessment and environmental monitoring: hurdles, achievements, and future outlook. Environ Health Perspect. (2010) 118:1-5. doi: 10.1289/ehp.0900985

245. Ichu T-A, Han J, Borchers CH, Lesperance M, Helbing CC. Metabolomic insights into system-wide coordination of vertebrate metamorphosis. BMC Dev Biol. (2014) 14:5. doi: 10.1186/1471-213X-14-5

246. Luehr TC, Koide EM, Wang X, Han J, Borchers CH, Helbing CC. Metabolomic insights into the effects of thyroid hormone on Rana [Lithobates] catesbeiana metamorphosis using whole-body Matrix Assisted Laser Desorption/Ionization-Mass Spectrometry Imaging (MALDI-MSI). Gen Comp Endocrinol. (2018) 265:237-45. doi: 10.1016/j.ygcen.2018. 02.012

247. Hammond SA, Warren RL, Vandervalk BP, Kucuk E, Khan H, Gibb EA, et al. The North American bullfrog draft genome provides insight into hormonal regulation of long noncoding RNA. Nat Commun. (2017) 8:7. doi: 10.1038/s41467-017-0 1316-7

248. Birol I, Behsaz B, Hammond SA, Kucuk E, Veldhoen N, Helbing CC. De novo transcriptome assemblies of Rana (Lithobates) catesbeiana and Xenopus laevis tadpole livers for comparative genomics without reference genomes. PLoS ONE. (2015) 10:e0130720. doi: 10.1371/journal.pone.013 0720

249. Session AM, Uno Y, Kwon T, Chapman JA, Toyoda A, Takahashi S, et al. Genome evolution in the allotetraploid frog Xenopus laevis. Nature. (2016) 538:336-43. doi: 10.1038/nature 19840

250. Buisine N, Ruan X, Bilesimo P, Grimaldi A, Alfama G, Ariyaratne $\mathrm{P}$, et al. Xenopus tropicalis genome re-scaffolding and re-annotation reach the resolution required for in vivo CHIA-PET analysis. PLoS ONE. (2015) 10:e137526. doi: 10.1371/journal.pone.013 7526

251. Sun Y-B, Xiong Z-J, Xiang X-Y, Liu S-P, Zhou W-W, Tu X-L, et al. Wholegenome sequence of the Tibetan frog Nanorana parkeri and the comparative evolution of tetrapod genomes. Proc Natl Acad Sci USA. (2015) 112:E125762. doi: $10.1073 /$ pnas.1501764112

252. Xu EG, Khursigara AJ, Magnuson J, Hazard ES, Hardiman G, Esbaugh AJ, et al. Larval red drum (Sciaenops ocellatus) sublethal exposure to weathered deepwater horizon crude oil: developmental and transcriptomic consequences. Environ Sci Technol. (2017) 51:10162-72. doi: 10.1021/acs.est.7b02037

253. Aeppli C, Carmichael CA, Nelson RK, Lemkau KL, Graham WM, Redmond MC, et al. Oil weathering after the Deepwater Horizon disaster led to the formation of oxygenated residues. Environ Sci Technol. (2012) 46:879907. doi: 10.1021/es3015138

254. Grimm FA, Hu D, Kania-Korwel I, Lehmler H-J, Ludewig G, Hornbuckle KC, Duffel MW, et al. Metabolism and metabolites of polychlorinated biphenyls. Crit Rev Toxicol. (2015) 45:245-72. doi: 10.3109/10408444.2014.999365

255. Hayes TB, Falso P, Gallipeau S, Stice M. The cause of global amphibian declines: a developmental endocrinologist's perspective. J Exp Biol. (2010) 213:921-933. doi: 10.1242/jeb.040865

256. Fini J-B, Mughal BB, Le Mével S, Leemans M, Lettmann M, Spirhanzlova $\mathrm{P}$, et al. Human amniotic fluid contaminants alter thyroid hormone signalling and early brain development in Xenopus embryos. Sci Rep. (2017) 7:43786. doi: $10.1038 /$ srep43786

257. Zoeller TR, Dowling ALS, Herzig CTA, Iannacone EA, Gauger KJ, Bansal R. Thyroid hormone, brain development, and the environment. Environ Health Perspect. (2002) 110(Suppl. 3):355-61. doi: 10.1289/ehp.02110s3355

Conflict of Interest Statement: The authors declare that the research was conducted in the absence of any commercial or financial relationships that could be construed as a potential conflict of interest.

Copyright (c) 2019 Thambirajah, Koide, Imbery and Helbing. This is an open-access article distributed under the terms of the Creative Commons Attribution License (CC $B Y)$. The use, distribution or reproduction in other forums is permitted, provided the original author(s) and the copyright owner(s) are credited and that the original publication in this journal is cited, in accordance with accepted academic practice. No use, distribution or reproduction is permitted which does not comply with these terms. 